\title{
24. X-RAY MINERALOGY DATA, SOUTHERN INDIAN OCEAN-LEG 26 DEEP SEA DRILLING PROJECT ${ }^{1}$
}

\author{
H. E. Cook, I. Zemmels, and J. C. Matti, Department of Geology, University of California, Riverside, California
}

\section{METHODS}

Semiquantitative determinations of the mineral composition of bulk samples, $2-20 \mu$ fractions, and $<2 \mu$ fractions were performed according to the methods described in the reports for Legs 1 and 2 and in Appendix III of Volume 4 of the Initial Reports of the Deep Sea Drilling Project. The mineral analyses of the $2-20 \mu$ and $<2 \mu$ fractions were performed on carbonate-free residues.

The X-ray-mineralogy results of this study are summarized in Tables 1 through 9. The mineralogy data are presented in Tables 10 through 20. Sediment ages, lithologic units, and nomenclature of the sediment types in Tables 1 through 9 are from the DSDP Leg 26 Hole Summaries and from a subsequent update supplied by Dr. T. A. Davies, DSDP. The stratigraphic positions of samples submitted for X-ray-diffraction analysis from Leg 26 are listed in Tables 1 through 9. The sample depth (in meters) below the sea floor in Tables 1 through 9 identifies the samples as they are reported in Tables 10 through 20.

Several unidentified minerals were detected in Leg 26 samples. Their abundances were determined on a semiqualitative basis using a hypothetical mineral intensity factor of 3.0. Unidentified minerals are reported on a ranked, semiqualitative scale outlined as follows: trace, $<5 \%$; present, 5 to $25 \%$; abundant, 25 to $65 \%$; major, $<65 \%$. Although a certain quantity of the unidentified minerals is implied, their concentration is not included in the concentrations of the identified minerals, which are summed to $100 \%$.

\section{DRILLING MUD USAGE}

Drilling mud, containing montmorillonite and barite, was used on Leg 26 as follows:

No mud was used at Sites $251,252,254,255,256$, or 257. In Hole $250 \mathrm{~A}$ drilling mud was used between Core 23 and Core 24; in Hole 253 between Core 33 and Core 34; and in Hole 258 between Core 17 and Core 18. Most samples submitted for X-ray-diffraction analysis do not occur close to intervals in which drilling mud was used. Barite does not occur in samples potentially contaminated by drilling mud, and montmorillonite abundances are not inordinate in any of these samples.

\section{MINERAL NOTES}

Garnet was found at Site 251 in pure calcite chalk (Sample 251A-29-2, 20-22 cm) overlying basalt. The garnet occurred as euhedral crystals, $2-5 \mu$ in diameter,

\footnotetext{
'Institute of Geophysics and Planetary Physics, University of California, Riverside, Contribution No. 7351.
}

loose as well as encased in calcite masses. The diffraction pattern closely resembles grossularite and has been tentatively identified to be hydrogrossularite by Dr. D. R. C. Kempe (this volume, Chapter 25).

The garnet was accompanied by an unusual occurrence of augites in the $<2 \mu$ fraction. The presence of about $78 \%$ augite was unequivocably determined in the diffraction pattern of the sample but could not be confirmed optically because of the fine-grained nature of the sample.

Augite was also found in large quantities in all samples submitted for X-ray-diffraction analysis from Site 252 (Tables 3 and 14). Augite was positively identified in the diffraction patterns of these samples. An optical examination showed that the crystalline component of the sample contained a large quantity of stubby, light green to colorless grains with good cleavage in two nearly orthogonal directions, highly inclined extinction and with all refractive indexes above 1.64. These grains were taken to be augite. Some of the grains showed saw-tooth etching on the ends of the cleavage fragments.

Anorthoclase and adularia were identified in the diffraction patterns of samples from the volcaniclastic sediments at Sites 253 and 254. The patterns match those of JCPDS 9-473 and 19-921, respectively. Optical confirmation could not be made because most of the sample consisted of devitrified glass and microcrystalline aggregates of uncertain origin with very few large, single-crystal grains present. Mordenite (JCPDS 11-155) was detected in a few samples from the Site 253 volcaniclastic sediments (Table 15).

Halite was frequently detected in the $<2 \mu$ fraction. This was found to be due to a contamination which was introduced during the sample preparation and should therefore be excluded from the total mineral content. The diffraction pattern of halite does not seriously interfere with other minerals and all minerals present in detectable concentrations have been reported in every case.

Montmorillonite was found frequently in the $2-20 \mu$ fraction. Microscopic examination of numerous samples showed that these preparations were not contaminated with $<2 \mu$ material but rather they contained microcrystalline aggregates which are presumed to be totally or in part made up of montmorillonite.

\section{ACKNOWLEDGMENTS}

The writers wish to acknowledge the excellent work of Nicki D. Coursey in the interpretation of X-ray diffraction data, of Paul D. Johnson in X-ray-data acquisition and data processing, and of Tom W. Halverson, Jr. in sample preparation. 
Summary of X-Ray Mineralogy Samples, Sample Depths, Lithology and Age of Lithologic Units, and X-Ray Diffraction Results, Site 250

\begin{tabular}{|c|c|c|c|c|c|c|c|c|c|c|c|}
\hline \multirow{2}{*}{$\begin{array}{c}\text { Sample } \\
\text { (Interval in cm) }\end{array}$} & \multirow{2}{*}{$\begin{array}{c}\text { Sample } \\
\text { Depth Below } \\
\text { Sea Floor (m) }\end{array}$} & \multirow[b]{2}{*}{ Lithology } & \multirow[b]{2}{*}{ Age } & \multicolumn{3}{|c|}{$\begin{array}{c}\text { Bulk Sample } \\
\text { Major Constituent }\end{array}$} & \multicolumn{2}{|c|}{$\begin{array}{c}2-20 \mu \text { Fraction } \\
\text { Major Constituent }\end{array}$} & \multicolumn{3}{|c|}{$\begin{array}{l}<2 \mu \text { Fraction } \\
\text { Major Constituent }\end{array}$} \\
\hline & & & & 1 & 2 & 3 & $\begin{array}{ll}1 & 2\end{array}$ & 3 & 1 & 2 & 3 \\
\hline $\begin{array}{l}250-1-1,93-95 \\
250-1-4,100-102 \\
250-1-5,100-102 \\
250-2-6,135-137 \\
\end{array}$ & $\begin{array}{r}0.9 \\
5.5 \\
7.0 \\
17.9 \\
\end{array}$ & $\begin{array}{c}\text { Unit } 1 \\
\text { Clayey coccolith } \\
\text { ooze and coccolith } \\
\text { detrital silty clay }\end{array}$ & Quaternary & $\begin{array}{l}\text { Mont. } \\
\text { Calc. } \\
\text { Mont. } \\
\text { Quar. }\end{array}$ & $\begin{array}{l}\text { Mica } \\
\text { Quar. } \\
\text { Quar. } \\
\text { Mica }\end{array}$ & $\begin{array}{l}\text { Quar. } \\
\text { Mont. } \\
\text { Mica } \\
\text { Mont. }\end{array}$ & $\begin{array}{ll}\text { Mica } & \text { Quar. } \\
\text { Quar. } & \text { Mica } \\
\text { Quar. } & \text { Mica } \\
\text { Quar. } & \text { Mica } \\
\end{array}$ & $\begin{array}{l}\text { K-Fe. } \\
\text { Plag. } \\
\text { Plag. } \\
\text { Plag. }\end{array}$ & $\begin{array}{l}\text { Mont. } \\
\text { Mont. } \\
\text { Mont. } \\
\text { Mont. }\end{array}$ & $\begin{array}{l}\text { Mica } \\
\text { Mica } \\
\text { Kaol. } \\
\text { Mica }\end{array}$ & $\begin{array}{l}\text { Kaol. } \\
\text { Kaol. } \\
\text { Mica } \\
\text { Quar. }\end{array}$ \\
\hline $\begin{array}{l}250 \mathrm{~A}-1-2,30-32 \\
250 \mathrm{~A}-1-3,32-34 \\
250 \mathrm{~A}-3-6,122-124\end{array}$ & $\begin{array}{l}56.3 \\
57.8 \\
82.2\end{array}$ & $\begin{array}{c}\text { Unit } 1 \\
\text { Clayey coccolith } \\
\text { ooze and coccolith } \\
\text { detrital silty clay }\end{array}$ & Quaternary & $\begin{array}{l}\text { Calc. } \\
\text { Mont. } \\
\text { Calc. }\end{array}$ & $\begin{array}{l}\text { Mont. } \\
\text { Mica } \\
\text { Mont. }\end{array}$ & $\begin{array}{l}\text { Mica } \\
\text { Quar. } \\
\text { Mica }\end{array}$ & $\begin{array}{ll}\text { Quar. } & \text { Mica } \\
\text { Quar. } & \text { Mica } \\
\text { Quar. } & \text { Mica }\end{array}$ & $\begin{array}{l}\text { Plag. } \\
\text { Plag. } \\
\text { Kaol. }\end{array}$ & $\begin{array}{l}\text { Mont. } \\
\text { Mont. } \\
\text { Mont. }\end{array}$ & $\begin{array}{l}\text { Quar. } \\
\text { Quar. } \\
\text { Kaol. }\end{array}$ & $\begin{array}{l}\text { Mica } \\
\text { Mica } \\
\text { Quar. }\end{array}$ \\
\hline $\begin{array}{l}250 \mathrm{~A}-4-4,144-146 \\
250 \mathrm{~A}-6-3,90-92 \\
250 \mathrm{~A}-7-1,10-12 \\
250 \mathrm{~A}-7-5,96-98 \\
250 \mathrm{~A}-8-1,30-32\end{array}$ & $\begin{array}{l}117.4 \\
191.4 \\
235.1 \\
242.0 \\
292.3\end{array}$ & $\begin{array}{c}\text { Unit } 2 \mathrm{~A} \\
\text { Detrital clays with } \\
\text { minor coccolith and } \\
\text { clay-rich coccolith } \\
\text { ooze }\end{array}$ & $\begin{array}{l}\text { Upper } \\
\text { Miocene- } \\
\text { upper } \\
\text { Pliocene }\end{array}$ & $\begin{array}{l}\text { Mont. } \\
\text { Mica } \\
\text { Mica } \\
\text { Mica } \\
\text { Mica }\end{array}$ & $\begin{array}{l}\text { Mica } \\
\text { Quar. } \\
\text { Mont. } \\
\text { Mont. } \\
\text { Mont. }\end{array}$ & $\begin{array}{l}\text { Quar. } \\
\text { Mont. } \\
\text { Quar. } \\
\text { Quar. } \\
\text { Quar. }\end{array}$ & $\begin{array}{ll}\text { Quar. } & \text { Mica } \\
\text { Quar. } & \text { Mica } \\
\text { Quar. } & \text { Mica } \\
\text { Quar. } & \text { Mica } \\
\text { Quar. } & \text { Mica }\end{array}$ & $\begin{array}{l}\text { Plag. } \\
\text { Plag. } \\
\text { Plag. } \\
\text { Plag. } \\
\text { Plag. }\end{array}$ & $\begin{array}{l}\text { Mont. } \\
\text { Mont. } \\
\text { Mica } \\
\text { Mont. } \\
\text { Mont. }\end{array}$ & $\begin{array}{l}\text { Quar. } \\
\text { Mica } \\
\text { Mont. } \\
\text { Mica } \\
\text { Mica }\end{array}$ & $\begin{array}{l}\text { Kaol. } \\
\text { Quar. } \\
\text { Quar. } \\
\text { Quar. } \\
\text { Quar. }\end{array}$ \\
\hline $\begin{array}{l}250 \mathrm{~A}-9-2,140-142 \\
250 \mathrm{~A}-10-2,10-12 \\
250 \mathrm{~A}-11-1,30-32 \\
250 \mathrm{~A}-11-5,120-122\end{array}$ & $\begin{array}{l}351.9 \\
407.6 \\
463.3 \\
470.2 \\
\end{array}$ & $\begin{array}{c}\text { Unit 2B } \\
\text { Detrital clays }\end{array}$ & $\begin{array}{c}\text { Lower- } \\
\text { middle } \\
\text { Miocene }\end{array}$ & $\begin{array}{l}\text { Mont. } \\
\text { Mica } \\
\text { Quar. } \\
\text { Quar. }\end{array}$ & $\begin{array}{l}\text { Quar. } \\
\text { Quar. } \\
\text { Mica } \\
\text { Mica }\end{array}$ & $\begin{array}{l}\text { Mica } \\
\text { Mont. } \\
\text { Mont. } \\
\text { Mont. }\end{array}$ & $\begin{array}{ll}\text { Quar. } & \text { Mica } \\
\text { Quar. } & \text { Mica } \\
\text { Quar. } & \text { Mica } \\
\text { Quar. } & \text { Plag. } \\
\end{array}$ & $\begin{array}{l}\text { Plag. } \\
\text { Plag. } \\
\text { Plag. } \\
\text { Mica }\end{array}$ & $\begin{array}{l}\text { Mont. } \\
\text { Mica } \\
\text { Mont. } \\
\text { Mont. }\end{array}$ & $\begin{array}{l}\text { Mica } \\
\text { Mont. } \\
\text { Mica } \\
\text { Mica } \\
\end{array}$ & $\begin{array}{l}\text { Quar. } \\
\text { Quar. } \\
\text { Quar. } \\
\text { Quar. }\end{array}$ \\
\hline $\begin{array}{l}250 \mathrm{~A}-13-1,75-77 \\
250 \mathrm{~A}-13-1,128-130 \\
250 \mathrm{~A}-14-2,22-24 \\
250 \mathrm{~A}-15-2,91-93\end{array}$ & $\begin{array}{l}568.3 \\
568.8 \\
607.2 \\
626.9 \\
\end{array}$ & $\begin{array}{c}\text { Unit } 3 \\
\text { Detrital clays }\end{array}$ & $\begin{array}{c}\text { Lower- } \\
\text { middle } \\
\text { Miocene }\end{array}$ & $\begin{array}{l}\text { Quar. } \\
\text { Quar. } \\
\text { Mont. } \\
\text { Quar. }\end{array}$ & $\begin{array}{l}\text { Mica } \\
\text { Mica } \\
\text { Quar. } \\
\text { Mont. }\end{array}$ & $\begin{array}{l}\text { Mont. } \\
\text { Mont. } \\
\text { Mica } \\
\text { Mica }\end{array}$ & $\begin{array}{ll}\text { Quar. } & \text { Plag. } \\
\text { Quar. } & \text { Plag. } \\
\text { Quar. } & \text { Plag. } \\
\text { Quar. } & \text { K-Fe. }\end{array}$ & $\begin{array}{l}\text { Mica } \\
\text { Mica } \\
\text { Mica } \\
\text { Mica } \\
\end{array}$ & $\begin{array}{l}\text { Mont. } \\
\text { Quar. } \\
\text { Mont. } \\
\text { Mont. }\end{array}$ & $\begin{array}{l}\text { Mica } \\
\text { Mica } \\
\text { Quar. } \\
\text { Mica } \\
\end{array}$ & $\begin{array}{l}\text { Quar. } \\
\text { Mont. } \\
\text { Mica } \\
\text { Quar. }\end{array}$ \\
\hline $\begin{array}{l}250 \mathrm{~A}-17-2,110-112 \\
250 \mathrm{~A}-19-2,33-35 \\
250 \mathrm{~A}-21-2,104-106 \\
250 \mathrm{~A}-23-1,95-97\end{array}$ & $\begin{array}{l}646.1 \\
664.3 \\
684.0 \\
701.5 \\
\end{array}$ & $\begin{array}{c}\text { Unit } 4 \\
\text { Detrital clays }\end{array}$ & $\begin{array}{c}\text { Coniacian } \\
\text { through } \\
\text { lower Miocene } \\
\end{array}$ & $\begin{array}{l}\text { Quar. } \\
\text { Paly. } \\
\text { Paly. } \\
\text { Cris. }\end{array}$ & $\begin{array}{l}\text { Mica } \\
\text { Mica } \\
\text { Mont. } \\
\text { Trid. } \\
\end{array}$ & $\begin{array}{l}\text { Mont. } \\
\text { Quar. } \\
\text { Quar. }\end{array}$ & $\begin{array}{ll}\text { Quar. } & \text { Mica } \\
\text { Quar. } & \text { Plag. } \\
\text { Quar. } & \text { Plag. } \\
\text { Cris. } & \text { Trid } \\
\end{array}$ & $\begin{array}{l}\text { Plag. } \\
\text { K-Fe. } \\
\text { Mica }\end{array}$ & $\begin{array}{l}\text { Mont. } \\
\text { Mont. } \\
\text { Mont. } \\
\text { Cris. }\end{array}$ & $\begin{array}{l}\text { Mica } \\
\text { Mica } \\
\text { Paly. } \\
\text { Trid. }\end{array}$ & $\begin{array}{l}\text { Paly. } \\
\text { Paly. } \\
\text { Quar. }\end{array}$ \\
\hline $\begin{array}{l}250 \mathrm{~A}-24-2,130-132 \\
250 \mathrm{~A}-25-1,22-24\end{array}$ & $\begin{array}{l}712.8 \\
719.7\end{array}$ & $\begin{array}{c}\text { Unit } 5 \\
\text { Detrital clays }\end{array}$ & Coniacian & $\begin{array}{l}\text { Paly. } \\
\text { Paly. }\end{array}$ & $\begin{array}{l}\text { Mont. } \\
\text { Mont. }\end{array}$ & $\begin{array}{l}\text { Quar. } \\
\text { Quar. }\end{array}$ & $\begin{array}{ll}\text { Quar. } & \text { Mica } \\
\text { Quar. } & \text { Mica }\end{array}$ & $\begin{array}{l}\text { Plag. } \\
\text { K-Fe. }\end{array}$ & $\begin{array}{l}\text { Mont. } \\
\text { Mont. }\end{array}$ & $\begin{array}{l}\text { Paly. } \\
\text { Paly. }\end{array}$ & $\begin{array}{l}\text { Quar. } \\
\text { Mica }\end{array}$ \\
\hline
\end{tabular}


TABLE 2

Summary of X-Ray Mineralogy Samples, Sample Depths, Lithology and Age of Lithologic Units, and X-Ray Diffraction Results, Site 251

\begin{tabular}{|c|c|c|c|c|c|c|c|c|c|}
\hline \multirow{2}{*}{$\begin{array}{c}\text { Sample } \\
\text { (Interval in } \mathrm{cm} \text { ) }\end{array}$} & \multirow{2}{*}{$\begin{array}{c}\text { Sample } \\
\text { Depth Below } \\
\text { Sea Floor }(m)\end{array}$} & \multirow[b]{2}{*}{ Lithology } & \multirow[b]{2}{*}{ Age } & \multirow{2}{*}{$\begin{array}{c}\begin{array}{c}\text { Bulk Sample } \\
\text { Major Constituent }\end{array} \\
2\end{array}$} & \multicolumn{2}{|c|}{$\begin{array}{l}2-20 \mu \text { Fraction } \\
\text { Major Constituent }\end{array}$} & \multicolumn{3}{|c|}{$\begin{array}{c}<2 \mu \text { Fraction } \\
\text { Major Constituent }\end{array}$} \\
\hline & & & & & $\begin{array}{ll}1 & 2\end{array}$ & 3 & 1 & 2 & 3 \\
\hline $251-1-1,94-96$ & 0.9 & $\begin{array}{c}\text { Unit } 1 \\
\text { Nannoplankton ooze }\end{array}$ & Quaternary & Calc. & Quar. Plag. & Mica & Mont. & Mica & Quar. \\
\hline $\begin{array}{l}251-3-1,126-128 \\
251-3-3,30-32 \\
251-5-5,70-72 \\
251-7-6,50-52 \\
251-10-5,22-24 \\
\end{array}$ & $\begin{array}{l}12.8 \\
14.8 \\
37.2 \\
57.5 \\
84.2 \\
\end{array}$ & $\begin{array}{c}\text { Unit 2A } \\
\text { Nannoplankton } \\
\text { ooze }\end{array}$ & $\begin{array}{l}\text { Upper Pliocene } \\
\text { through } \\
\text { Quaternary }\end{array}$ & $\begin{array}{l}\text { Calc. } \\
\text { Calc. } \\
\text { Calc. } \\
\text { Calc. } \\
\text { Calc. }\end{array}$ & $\begin{array}{l}\text { Quar. Plag. } \\
\text { Quar. Plag. } \\
\text { Quar. Plag. } \\
\text { Quar. Plag. } \\
\text { Quar. Plag. }\end{array}$ & $\begin{array}{l}\text { Mica } \\
\text { Mica } \\
\text { Mica } \\
\text { Mica } \\
\text { Mica }\end{array}$ & $\begin{array}{l}\text { Mont. } \\
\text { Mont. } \\
\text { Mont. } \\
\text { Mont. } \\
\text { Mont. }\end{array}$ & $\begin{array}{l}\text { Mica } \\
\text { Quar. } \\
\text { Mica } \\
\text { Quar. } \\
\text { Mica }\end{array}$ & $\begin{array}{l}\text { Quar. } \\
\text { Mica } \\
\text { Quar. } \\
\text { Mica } \\
\text { Quar. }\end{array}$ \\
\hline $251 \mathrm{~A}-1-6,30-32$ & 85.8 & $\begin{array}{c}\text { Unit } 2 \mathrm{~A} \\
\text { Nannoplankton ooze }\end{array}$ & $\begin{array}{c}\text { Upper } \\
\text { Pliocene } \\
\end{array}$ & Calc. & Quar. Plag. & Mica & Mica & Mont. & Quar. \\
\hline $\begin{array}{l}251 \mathrm{~A}-4-6,20-22 \\
251 \mathrm{~A}-6-6,20-22 \\
251 \mathrm{~A}-9-4,20-22 \\
251 \mathrm{~A}-12-6,20-22\end{array}$ & $\begin{array}{l}114.2 \\
133.2 \\
158.7 \\
228.2 \\
\end{array}$ & $\begin{array}{c}\text { Unit 2B } \\
\text { Nannoplankton ooze } \\
\text { with increased } \\
\text { detrital components }\end{array}$ & $\begin{array}{l}\text { Upper } \\
\text { Miocene- } \\
\text { lower } \\
\text { Pliocene }\end{array}$ & $\begin{array}{l}\text { Calc. } \\
\text { Calc. } \\
\text { Calc. } \\
\text { Calc. }\end{array}$ & $\begin{array}{ll}\text { Quar. } & \text { Plag. } \\
\text { Quar. Plag. } \\
\text { Quar. Plag. } \\
\text { Quar. } \\
\end{array}$ & $\begin{array}{l}\text { Mica } \\
\text { Mica } \\
\text { Mica } \\
\text { Plag. }\end{array}$ & $\begin{array}{l}\text { Mont. } \\
\text { Mont. } \\
\text { Mont. } \\
\text { Mont. }\end{array}$ & $\begin{array}{l}\text { Mica } \\
\text { Mica } \\
\text { Mica } \\
\text { Mica }\end{array}$ & $\begin{array}{l}\text { Quar. } \\
\text { Quar. } \\
\text { Quar. } \\
\text { Quar. }\end{array}$ \\
\hline $\begin{array}{l}251 \mathrm{~A}-15-3,28-30 \\
251 \mathrm{~A}-18-1,57-59 \\
251 \mathrm{~A}-20-6,25-27 \\
251 \mathrm{~A}-22-3,100-102 \\
251 \mathrm{~A}-24-4,134-136 \\
251 \mathrm{~A}-26-4,3-5\end{array}$ & $\begin{array}{l}309.3 \\
373.1 \\
399.3 \\
414.5 \\
435.3 \\
453.0\end{array}$ & $\begin{array}{c}\text { Unit } 3 \\
\text { Nannoplankton } \\
\text { ooze }\end{array}$ & $\begin{array}{l}\text { Lower } \\
\text { and middle } \\
\text { Miocene }\end{array}$ & $\begin{array}{l}\text { Calc. } \\
\text { Calc. } \\
\text { Calc. } \\
\text { Calc. } \\
\text { Calc. } \\
\text { Calc. }\end{array}$ & $\begin{array}{ll}\text { Quar. } & \text { Plag. } \\
\text { Quar. } & \text { Mica } \\
\text { Quar. } & \text { Mica } \\
\text { Quar. } & \text { Mica } \\
\text { Quar. } & \text { Mica } \\
\text { Quar. } & \text { Mica }\end{array}$ & $\begin{array}{l}\text { Mica } \\
\text { Plag. } \\
\text { Plag. } \\
\text { Plag. } \\
\text { Plag. } \\
\text { Plag. }\end{array}$ & $\begin{array}{l}\text { Mont. } \\
\text { Mont. } \\
\text { Mont. } \\
\text { Mont. } \\
\text { Mont. } \\
\text { Paly. }\end{array}$ & $\begin{array}{l}\text { Mica } \\
\text { Mica } \\
\text { Mica } \\
\text { Mica } \\
\text { Mica } \\
\text { Mont. }\end{array}$ & $\begin{array}{l}\text { Quar. } \\
\text { Quar. } \\
\text { Quar. } \\
\text { Quar. } \\
\text { Quar. } \\
\text { Quar. }\end{array}$ \\
\hline $251 \mathrm{~A}-26-4,120-122$ & 454.2 & $\begin{array}{c}\text { Unit } 4 \\
\text { Nanno chalk }\end{array}$ & $\begin{array}{c}\text { Lower } \\
\text { Miocene }\end{array}$ & Calc. & Quar. Plag. & Mica & Mica & Quar. & Mont. \\
\hline $251 \mathrm{~A}-29-2,20-22$ & 478.7 & $\begin{array}{c}\text { Unit } 5 \\
\text { Calcite (micarb) chalk }\end{array}$ & $\begin{array}{c}\text { Lower } \\
\text { Miocene }\end{array}$ & Calc. & U-9 & & Augi. & Mont. & U-9 \\
\hline
\end{tabular}


TABLE 3

Summary of X-Ray Mineralogy Samples, Sample Depths, Lithology and Age of Lithologic Units, and X-Ray Diffraction Results, Site 252

\begin{tabular}{|c|c|c|c|c|c|c|c|c|c|}
\hline \multirow{2}{*}{$\begin{array}{c}\text { Sample } \\
\text { (Interval in } \mathrm{cm} \text { ) }\end{array}$} & \multirow{2}{*}{$\begin{array}{c}\text { Sample } \\
\text { Depth Below } \\
\text { Sea Floor (m) }\end{array}$} & \multirow[b]{2}{*}{ Lithology } & \multirow[b]{2}{*}{ Age } & \multicolumn{2}{|c|}{$\begin{array}{c}\text { Bulk Sample } \\
\text { Major Constituent }\end{array}$} & \multicolumn{2}{|c|}{$\begin{array}{l}2-20 \mu \text { Fraction } \\
\text { Major Constituent }\end{array}$} & \multicolumn{2}{|c|}{$\begin{array}{c}<2 \mu \text { Fraction } \\
\text { Major Constituent }\end{array}$} \\
\hline & & & & 12 & 3 & 12 & 3 & $\begin{array}{ll}1 & 2\end{array}$ & 3 \\
\hline $\begin{array}{l}252-2-2,30-32 \\
252-2-3,73-75\end{array}$ & $\begin{array}{l}1.8 \\
3.7\end{array}$ & $\begin{array}{c}\text { Unit } 1 \\
\text { Radiolarian clay } \\
\text { and silty clay }\end{array}$ & Quaternary & $\begin{array}{ll}\text { Plag. } & \text { Augi. } \\
\text { Augi. } & \text { Plag. }\end{array}$ & $\begin{array}{l}\text { K-Fe. } \\
\text { Mont. }\end{array}$ & $\begin{array}{ll}\text { Augi. } & \text { Plag. } \\
\text { Augi. } & \text { Plag. }\end{array}$ & $\begin{array}{l}\text { K-Fe. } \\
\text { Quar. }\end{array}$ & $\begin{array}{l}\text { Mont. Plag. } \\
\text { Mont. Pyri. }\end{array}$ & $\begin{array}{l}\text { Mica } \\
\text { Mica }\end{array}$ \\
\hline $\begin{array}{l}252-4-6,120-122 \\
252-6-3,120-122 \\
252-7-2,138-140\end{array}$ & $\begin{array}{l}103.7 \\
194.2 \\
240.4\end{array}$ & $\begin{array}{c}\text { Unit } 2 \\
\text { Diatom-bearing } \\
\text { radiolarian clay }\end{array}$ & $\begin{array}{l}\text { Miocene } \\
\text { through } \\
\text { Quaternary }\end{array}$ & $\begin{array}{ll}\text { Augi. } & \text { Plag. } \\
\text { Augi. } & \text { Plag. } \\
\text { Augi. } & \text { Mont. }\end{array}$ & $\begin{array}{l}\text { Mont. } \\
\text { Mont. } \\
\text { Plag. }\end{array}$ & $\begin{array}{ll}\text { Augi. } & \text { Plag. } \\
\text { Augi. } & \text { Plag. } \\
\text { Augi. } & \text { Plag. }\end{array}$ & $\begin{array}{l}\text { Quar. } \\
\text { Quar. } \\
\text { Quar. }\end{array}$ & $\begin{array}{l}\text { Mont. Mica } \\
\text { Mont. Plag. } \\
\text { Mont. Mica }\end{array}$ & $\begin{array}{l}\text { Plag. } \\
\text { Mica } \\
\text { Plag. }\end{array}$ \\
\hline
\end{tabular}

TABLE 4

Summary of X-Ray Mineralogy Samples, Sample Depths, Lithology and Age of Lithologic Units, and X-Ray Diffraction Results, Site 253

\begin{tabular}{|c|c|c|c|c|c|c|c|c|}
\hline \multirow{2}{*}{$\begin{array}{c}\text { Sample } \\
\text { (Interval in } \mathrm{cm} \text { ) }\end{array}$} & \multirow{2}{*}{$\begin{array}{c}\text { Sample } \\
\text { Depth Below } \\
\text { Sea Floor }(m)\end{array}$} & \multirow[b]{2}{*}{ Lithology } & \multirow[b]{2}{*}{ Age } & \multicolumn{2}{|c|}{$\begin{array}{c}\text { Bulk Sample } \\
\text { Major Constituent }\end{array}$} & \multicolumn{2}{|c|}{$\begin{array}{l}2-20 \mu \text { Fraction } \\
\text { Major Constituent }\end{array}$} & $\begin{array}{l}<2 \mu \text { Fraction } \\
\text { Major Constituent }\end{array}$ \\
\hline & & & & 12 & 3 & $\begin{array}{ll}1 & 2\end{array}$ & 3 & $\begin{array}{lll}1 & 2 & 3\end{array}$ \\
\hline $253-1-2,115-117$ & 2.6 & $\begin{array}{c}\text { Unit } 1 \\
\text { Nannoforam ooze }\end{array}$ & Quaternary & Calc. & & Quar. Gyps. & Mica & Mica Quar. Mont. \\
\hline $\begin{array}{l}253-5-6,70-72 \\
253-7-2,87-88 \\
253-9-4,93-95 \\
253-11-2,93-95 \\
253-13-2,93-95 \\
253-16-6,139-141\end{array}$ & $\begin{array}{r}45.7 \\
58.9 \\
80.9 \\
96.9 \\
115.9 \\
150.9 \\
\end{array}$ & $\begin{array}{c}\text { Unit } 2 \\
\text { Foraminiferal- } \\
\text { nannoplankton } \\
\text { ooze }\end{array}$ & $\begin{array}{l}\text { Upper } \\
\text { Eocene } \\
\text { through } \\
\text { Pliocene }\end{array}$ & $\begin{array}{l}\text { Calc. } \\
\text { Calc. } \\
\text { Calc. } \\
\text { Calc. } \\
\text { Calc. } \\
\text { Calc. } \\
\end{array}$ & & $\begin{array}{l}\text { Insufficient res } \\
\text { Insufficient res } \\
\mathrm{K}-\mathrm{Fe} \text {. Quar. } \\
\text { Insufficient resi } \\
\mathrm{K}-\mathrm{Fe} \text {. Quar. } \\
\mathrm{Clin} \text {. Gyps. } \\
\end{array}$ & $\begin{array}{l}\text { sidue } \\
\text { sidue } \\
\text { Mica } \\
\text { sidue } \\
\text { Mica } \\
\text { Mont. }\end{array}$ & $\begin{array}{l}\text { Insufficient residue } \\
\text { Mica Quar. Mont. } \\
\text { Paly. Mont. K-Fe. } \\
\text { Insufficient residue } \\
\text { Paly. Mont. } \\
\text { Mont. }\end{array}$ \\
\hline $\begin{array}{l}253-17-2,114-116 \\
253-18-2,92-94 \\
253-18-4,8-10 \\
253-20-2,100-102 \\
253-23-2,93-95 \\
253-25-2,93-95 \\
253-30-1,110-112 \\
253-31-2,110-112 \\
253-36-1,130-132 \\
253-38-1,96-98 \\
253-40-2,45-47 \\
253-42-2,135-137 \\
253-44-2,8-10 \\
253-46-2,100-102 \\
253-48-2,56-58 \\
253-49-2,58-59 \\
253-51-2,41-43 \\
253-52-2,135-137 \\
253-54-2,121-123 \\
253-56-2,117-119 \\
253-57-2,68-71\end{array}$ & $\begin{array}{l}154.1 \\
163.4 \\
165.6 \\
182.5 \\
210.9 \\
229.9 \\
270.6 \\
281.6 \\
327.8 \\
346.5 \\
366.5 \\
386.4 \\
404.1 \\
424.0 \\
442.6 \\
452.1 \\
470.9 \\
481.3 \\
500.2 \\
519.2 \\
547.2\end{array}$ & $\begin{array}{c}\text { Unit } 3 \\
\text { Vitric volcanic } \\
\text { ash and } \\
\text { lapilli with } \\
\text { calcareous } \\
\text { components }\end{array}$ & $\begin{array}{l}\text { Middle } \\
\text { Eocene }\end{array}$ & $\begin{array}{l}\text { Mont. Plag. } \\
\text { Calc. Mont. } \\
\text { Calc. Mont. } \\
\text { Calc. Mont. } \\
\text { Calc. Mont. } \\
\text { Mont. Calc. } \\
\text { Calc. Clin. } \\
\text { Calc. Mont. } \\
\text { Mont. Clin. } \\
\text { Mont. Calc. } \\
\text { Mont. Calc. } \\
\text { Mont. Clin. } \\
\text { Mont. Calc. } \\
\text { Mont. Calc. } \\
\text { Mont. Anal. } \\
\text { Mont. Anal. } \\
\text { Mont. Calc. } \\
\text { Mont. Anal. } \\
\text { Mont. Anal. } \\
\text { Mont. Kaol. } \\
\text { Mont. Cris. }\end{array}$ & $\begin{array}{l}\text { Magn. } \\
\text { Augi. } \\
\text { Phil. } \\
\text { Phil. } \\
\text { Clin. } \\
\text { Clin. }\end{array}$ & $\begin{array}{l}\text { Mont. Magn. } \\
\text { Mont. Plag. } \\
\text { Mont. Augi. } \\
\text { Mont. Pyri. } \\
\text { Mont. Phil. } \\
\text { Mont. Phil. } \\
\text { Clin. Plag. } \\
\text { Mont. Plag. } \\
\text { Clin. Mont. } \\
\text { Mont. Clin. } \\
\text { Mont. Anal. } \\
\text { Mont. Clin. } \\
\text { Mont. } \\
\text { Mont. Clin. } \\
\text { Mont. Anal. } \\
\text { Mont. Anal. } \\
\text { Mont. Anal. } \\
\text { Anal. Mont. } \\
\text { Mont. Anal. } \\
\text { Mont. Clin. } \\
\text { Mont. Cris. }\end{array}$ & $\begin{array}{l}\text { Mont. } \\
\text { Clin. } \\
\text { Magn. } \\
\text { Anal. } \\
\text { Clin. } \\
\text { Quar. }\end{array}$ & $\begin{array}{l}\text { Mont. } \\
\text { Mont. } \\
\text { Mont. Augi. } \\
\text { Mont. } \\
\text { Mont. Phil. } \\
\text { Mont. } \\
\text { Mont. Mica } \\
\text { Mont. } \\
\text { Mont. } \\
\text { Mont. } \\
\text { Mont. } \\
\text { Mont. } \\
\text { Mont. } \\
\text { Mont. } \\
\text { Mont. } \\
\text { Mont. } \\
\text { Mont. } \\
\text { Mont. } \\
\text { Mont. } \\
\text { Mont. } \\
\text { Mont. Cris. }\end{array}$ \\
\hline
\end{tabular}


TABLE 5

Summary of X-Ray Mineralogy Samples, Sample Depths, Lithology and Age of Lithologic Units, and X-Ray Diffraction Results, Site 254

\begin{tabular}{|c|c|c|c|c|c|c|c|c|}
\hline \multirow{2}{*}{$\begin{array}{c}\text { Sample } \\
\text { (Interval in } \mathrm{cm} \text { ) }\end{array}$} & \multirow{2}{*}{$\begin{array}{c}\text { Sample } \\
\text { Depth Below } \\
\text { Sea Floor }(\mathrm{m})\end{array}$} & \multirow[b]{2}{*}{ Lithology } & \multirow[b]{2}{*}{ Age } & \multicolumn{2}{|c|}{$\begin{array}{c}\text { Bulk Sample } \\
\text { Major Constituent }\end{array}$} & $\begin{array}{l}2-20 \mu \text { Fraction } \\
\text { Major Constituent }\end{array}$ & \multicolumn{2}{|c|}{$\begin{array}{l}<2 \mu \text { Fraction } \\
\text { Major Constituent }\end{array}$} \\
\hline & & & & 12 & 3 & $\begin{array}{lll}1 & 2 & 3\end{array}$ & $1 \quad 2$ & 3 \\
\hline $254-2-2,92-94$ & 7.9 & $\begin{array}{c}\text { Unit } 1 \\
\text { Coccolith foram ooze }\end{array}$ & $\begin{array}{l}\text { Pliocene- } \\
\text { Quaternary }\end{array}$ & Calc. & & Insufficient residue & Mont. Mica & Quar. \\
\hline $\begin{array}{l}254-2-5,92-94 \\
254-4-2,92-94 \\
254-7-5,94-96 \\
254-10-5,10-12\end{array}$ & $\begin{array}{l}12.4 \\
26.9 \\
59.9 \\
87.6\end{array}$ & $\begin{array}{l}\text { Unit 2A } \\
\text { Foram-rich } \\
\text { coccolith } \\
\text { ooze }\end{array}$ & $\begin{array}{l}\text { Middle } \\
\text { Miocene } \\
\text { through } \\
\text { Pliocene }\end{array}$ & $\begin{array}{l}\text { Calc. } \\
\text { Calc. } \\
\text { Calc. } \\
\text { Calc. }\end{array}$ & & Insufficient residue & $\begin{array}{l}\text { Mont. } \\
\text { Mont. Mica } \\
\text { Quar. Mont. } \\
\text { Mica Mont. }\end{array}$ & Quar. \\
\hline $254-18-5,92-94$ & 154.9 & $\begin{array}{c}\text { Unit } 2 \mathrm{C} \\
\text { Calcareous ooze }\end{array}$ & $\begin{array}{c}\text { Lower } \\
\text { Miocene }\end{array}$ & Calc. & & Phil. & Mont. Mica & Quar. \\
\hline $\begin{array}{l}254-20-2,54-56 \\
254-20-2,125-127\end{array}$ & $\begin{array}{l}169.0 \\
169.8\end{array}$ & $\begin{array}{l}\text { Unit 2D } \\
\text { Foram and coccolith } \\
\text { micarb ooze }\end{array}$ & Oligocene & $\begin{array}{l}\text { Calc. } \\
\text { Calc. }\end{array}$ & & $\begin{array}{lll}\text { Anal. } & \text { Phil. } & \text { Mont. } \\
\text { Phil. } & \text { Mont. } & \text { Magn. }\end{array}$ & $\begin{array}{l}\text { Mont. Magn. } \\
\text { Mont. Magn. }\end{array}$ & Magn. \\
\hline $\begin{array}{l}254-24-1,110-111 \\
254-25-5,70-72 \\
254-27-3,123-125 \\
254-30-1,120-125\end{array}$ & $\begin{array}{l}210.6 \\
225.7 \\
242.2 \\
267.7\end{array}$ & $\begin{array}{c}\text { Unit } 4 \\
\text { Sandy and silty } \\
\text { clays and silty } \\
\text { sands and pebble } \\
\text { conglomerates }\end{array}$ & $\begin{array}{l}\text { Upper } \\
\text { Eocene } \\
\text { or lower } \\
\text { Oligocene }\end{array}$ & $\begin{array}{l}\text { Mont. Phil. } \\
\text { Mont. Phil. } \\
\text { Mont. Pyri. } \\
\text { Mont. }\end{array}$ & $\begin{array}{l}\text { Pyri. } \\
\text { Pyri. } \\
\text { Phil. }\end{array}$ & $\begin{array}{l}\text { Mont. Pyri. } \\
\text { Pyri. Mont. Phil. } \\
\text { Pyri. Phil. Clin. } \\
\text { Mont. }\end{array}$ & $\begin{array}{l}\text { Mont. } \\
\text { Mont. } \\
\text { Mont. Pyri. } \\
\text { Mont. }\end{array}$ & Pyri. \\
\hline
\end{tabular}

TABLE 6

Summary of X-Ray Mineralogy Sample, Sample Depth, Lithology and Age of Lithologic Unit, and X-Ray Diffraction Results, Site 255

\begin{tabular}{|c|c|c|c|c|c|c|c|}
\hline \multirow{2}{*}{$\begin{array}{c}\text { Sample } \\
\text { (Interval in } \mathrm{cm} \text { ) }\end{array}$} & \multirow{2}{*}{$\begin{array}{c}\text { Sample } \\
\text { Depth Below } \\
\text { Sea Floor (m) }\end{array}$} & \multirow[b]{2}{*}{ Lithology } & \multirow[b]{2}{*}{ Age } & $\begin{array}{c}\text { Bulk Sample } \\
\text { Major Constituent }\end{array}$ & $\begin{array}{l}\text { 2-20 } \mu \text { Fraction } \\
\text { Major Constituent }\end{array}$ & \multicolumn{2}{|c|}{$\begin{array}{c}<2 \mu \text { Fraction } \\
\text { Major Constituent }\end{array}$} \\
\hline & & & & $\begin{array}{lll}1 & 2 & 3\end{array}$ & $\begin{array}{lll}1 & 2 & 3\end{array}$ & 112 & 3 \\
\hline $255-5-1,130-132$ & 43.3 & $\begin{array}{c}\text { Unit 1 } \\
\text { Nannoplankton } \\
\text { foram ooze }\end{array}$ & $\begin{array}{c}\text { Lower } \\
\text { Miocene }\end{array}$ & Calc. & Phil. Quar. Anal. & Quar. & $\mathrm{V}-2$ \\
\hline
\end{tabular}

TABLE 7

Summary of X-Ray Mineralogy Samples, Sample Depths, Lithology and Age of Lithologic Units, and X-Ray Diffraction Results, Site 256

\begin{tabular}{|c|c|c|c|c|c|c|c|c|c|c|c|c|}
\hline \multirow{2}{*}{$\begin{array}{c}\text { Sample } \\
\text { (Interval in cm) }\end{array}$} & \multirow{2}{*}{$\begin{array}{c}\text { Sample } \\
\text { Depth Below } \\
\text { Sea Floor (m) }\end{array}$} & \multirow[b]{2}{*}{ Lithology } & \multirow[b]{2}{*}{ Age } & \multicolumn{3}{|c|}{$\begin{array}{c}\text { Bulk Sample } \\
\text { Major Constituent }\end{array}$} & \multicolumn{3}{|c|}{$\begin{array}{l}2-20 \mu \text { Fraction } \\
\text { Major Constituent }\end{array}$} & \multicolumn{3}{|c|}{$\begin{array}{l}<2 \mu \text { Fraction } \\
\text { Major Constituent }\end{array}$} \\
\hline & & & & & 2 & 3 & & 2 & 3 & 1 & 2 & 3 \\
\hline $\begin{array}{l}256-1-5,89-91 \\
256-3-5,45-47 \\
256-4-6,120-122 \\
256-5-4,85-87 \\
256-7-3,127-129 \\
256-8-5,105-107 \\
256-9-1,133-135\end{array}$ & $\begin{array}{r}6.9 \\
54.0 \\
94.2 \\
128.9 \\
213.3 \\
244.6 \\
248.3\end{array}$ & $\begin{array}{l}\text { Unit } 1 \\
\text { Detrital } \\
\text { clays }\end{array}$ & $\begin{array}{c}\text { Albian } \\
\text { through } \\
\text { Quaternary }\end{array}$ & $\begin{array}{l}\text { Mont. } \\
\text { Mont. } \\
\text { Mont. } \\
\text { Mica } \\
\text { Cris. } \\
\text { Clin. } \\
\text { Calc. }\end{array}$ & $\begin{array}{l}\text { Kaol. } \\
\text { Kaol. } \\
\text { Kaol. } \\
\text { Mont. } \\
\text { Clin. } \\
\text { Cris. } \\
\text { Mont. }\end{array}$ & $\begin{array}{l}\text { Mica } \\
\text { Mica } \\
\text { Mica } \\
\text { Kaol. } \\
\text { Mica } \\
\text { Mica } \\
\text { Quar. }\end{array}$ & $\begin{array}{l}\text { Quar. } \\
\text { Mica } \\
\text { Mica } \\
\text { Quar. } \\
\text { Cris. } \\
\text { Clin. } \\
\text { Quar. }\end{array}$ & $\begin{array}{l}\text { Mica } \\
\text { Quar. } \\
\text { Mont. } \\
\text { Mica } \\
\text { Clin. } \\
\text { Quar. } \\
\text { Mont. }\end{array}$ & $\begin{array}{l}\text { Kaol. } \\
\text { Mont. } \\
\text { Quar. } \\
\text { K-Fe. } \\
\text { Quar. } \\
\text { K-Fe. } \\
\text { K-Fe. }\end{array}$ & $\begin{array}{l}\text { Mont. } \\
\text { Mont. } \\
\text { Mont. } \\
\text { Mica } \\
\text { Cris. } \\
\text { Cris. } \\
\text { Mont. }\end{array}$ & $\begin{array}{l}\text { Quar. } \\
\text { Kaol. } \\
\text { Kaol. } \\
\text { Mont. } \\
\text { Quar. } \\
\text { Mont. } \\
\text { Quar. }\end{array}$ & $\begin{array}{l}\text { Kaol. } \\
\text { Quar. } \\
\text { Mica } \\
\text { Quar. } \\
\text { Mont. } \\
\text { Mica } \\
\text { K-Fe. }\end{array}$ \\
\hline
\end{tabular}


TABLE 8

Summary of X-Ray Mineralogy Samples, Sample Depths, Lithology and Age of Lithologic Units, and X-Ray Diffraction Results, Site 257

\begin{tabular}{|c|c|c|c|c|c|c|c|c|c|c|c|}
\hline \multirow{2}{*}{$\begin{array}{c}\text { Sample } \\
\text { (Interval in cm) }\end{array}$} & \multirow{2}{*}{$\begin{array}{c}\text { Sample } \\
\text { Depth Below } \\
\text { Sea Floor }(\mathrm{m})\end{array}$} & \multirow[b]{2}{*}{ Lithology } & \multirow[b]{2}{*}{ Age } & \multicolumn{2}{|c|}{$\begin{array}{c}\text { Bulk Sample } \\
\text { Major Constituent }\end{array}$} & \multicolumn{3}{|c|}{$\begin{array}{l}\text { 2-20 } \mu \text { Fraction } \\
\text { Major Constituent }\end{array}$} & \multicolumn{3}{|c|}{$\begin{array}{l}<2 \mu \text { Fraction } \\
\text { Major Constituent }\end{array}$} \\
\hline & & & & 12 & 3 & & 2 & 3 & & 2 & 3 \\
\hline $\begin{array}{l}257-1-5,93-95 \\
257-2-2,128-130 \\
257-3-3,116-118 \\
257-4-4,24-26 \\
257-5-2,93-95 \\
257-6-1,133-135\end{array}$ & $\begin{array}{r}6.9 \\
12.3 \\
51.7 \\
90.2 \\
125.9 \\
162.8 \\
\end{array}$ & $\begin{array}{c}\text { Unit } 1 \mathrm{~A} \\
\text { Detrital clay and } \\
\text { coccolith detrital } \\
\text { clay }\end{array}$ & $\begin{array}{c}\text { Cretaceous } \\
\text { and } \\
\text { Tertiary }\end{array}$ & $\begin{array}{l}\text { Mont. } \\
\text { Mont. } \\
\text { Mont. } \\
\text { Mont. } \\
\text { Clin. } \\
\text { Mont. }\end{array}$ & $\begin{array}{l}\text { Quar. } \\
\text { Kaol. } \\
\text { Mica } \\
\text { Mica } \\
\text { Mica } \\
\text { Mica } \\
\end{array}$ & $\begin{array}{l}\text { Quar. } \\
\text { Quar. } \\
\text { Quar. } \\
\text { Clin. } \\
\text { Clin. } \\
\text { Clin. }\end{array}$ & $\begin{array}{l}\text { Plag. } \\
\text { Mica } \\
\text { Mica } \\
\text { Mica } \\
\text { Mont. } \\
\text { K-Fe. }\end{array}$ & $\begin{array}{l}\text { Mica } \\
\text { Clin. } \\
\text { Kaol. } \\
\text { Quar. } \\
\text { Quar. } \\
\text { Mica }\end{array}$ & $\begin{array}{l}\text { Mont. } \\
\text { Mont. } \\
\text { Mont. } \\
\text { Mont. } \\
\text { Mont. } \\
\text { Mont. }\end{array}$ & $\begin{array}{l}\text { Quar. } \\
\text { Kaol. } \\
\text { Quar. } \\
\text { Cris. } \\
\text { Clin. } \\
\text { Clin. }\end{array}$ & $\begin{array}{l}\text { Mica } \\
\text { Mica } \\
\text { Kaol. } \\
\text { Clin. } \\
\text { Cris. } \\
\text { K-Fe. }\end{array}$ \\
\hline $\begin{array}{l}257-7-2,93-95 \\
257-8-2,92-94\end{array}$ & $\begin{array}{l}201.9 \\
239.5\end{array}$ & $\begin{array}{c}\text { Unit 1B } \\
\text { Detrital clay }\end{array}$ & $\begin{array}{l}\text { Middle } \\
\text { Albian }\end{array}$ & $\begin{array}{ll}\text { Mont. } & \text { Calc. } \\
\text { Mont. } & \mathrm{K}-\mathrm{Fe} .\end{array}$ & $\begin{array}{l}\text { K-Fe. } \\
\text { Quar. }\end{array}$ & $\begin{array}{l}\mathrm{K}-\mathrm{Fe} . \\
\mathrm{K}-\mathrm{Fe} .\end{array}$ & $\begin{array}{l}\text { Mica } \\
\text { Quar. }\end{array}$ & $\begin{array}{l}\text { Quar. } \\
\text { Mont. }\end{array}$ & \multicolumn{3}{|c|}{$\begin{array}{l}\text { Insufficient residue } \\
\text { Mont. Quar. K-Fe. }\end{array}$} \\
\hline $\begin{array}{l}257-9-2,104-106 \\
257-10-1,92-94\end{array}$ & $\begin{array}{l}249.5 \\
257.4\end{array}$ & $\begin{array}{c}\text { Unit } 1 \mathrm{C} \\
\text { Detrital clay }\end{array}$ & ? Cretaeous & $\begin{array}{ll}\text { Mont. } & \text { Quar. } \\
\text { Mont. } & \text { Quar. }\end{array}$ & Mica & $\begin{array}{l}\text { Mont. } \\
\text { Quar. }\end{array}$ & $\begin{array}{l}\text { Quar. } \\
\text { Mont. }\end{array}$ & $\begin{array}{l}\text { Mica } \\
\text { Mica }\end{array}$ & $\begin{array}{l}\text { Mont. } \\
\text { Quar. }\end{array}$ & $\begin{array}{l}\text { Mica } \\
\text { Mont. }\end{array}$ & Quar. \\
\hline
\end{tabular}

TABLE 9

Summary of X-Ray Mineralogy Samples, Sample Depths, Lithology and Age of Lithologic Units, and X-Ray Diffraction Results, Site 258

\begin{tabular}{|c|c|c|c|c|c|c|c|c|c|c|c|}
\hline \multirow{2}{*}{$\begin{array}{c}\text { Sample } \\
\text { (Interval in cm) }\end{array}$} & \multirow{2}{*}{$\begin{array}{c}\text { Sample } \\
\text { Depth Below } \\
\text { Sea Floor }(\mathrm{m})\end{array}$} & \multirow[b]{2}{*}{ Lithology } & \multirow[b]{2}{*}{ Age } & \multicolumn{2}{|c|}{$\begin{array}{c}\text { Bulk Sample } \\
\text { Major Constituent }\end{array}$} & \multicolumn{3}{|c|}{$\begin{array}{l}2-20 \mu \text { Fraction } \\
\text { Major Constituent }\end{array}$} & \multicolumn{3}{|c|}{$\begin{array}{l}<2 \mu \text { Fraction } \\
\text { Major Constituent }\end{array}$} \\
\hline & & & & $\begin{array}{ll}1 & 2\end{array}$ & 3 & & 2 & 3 & 1 & 2 & 3 \\
\hline $\begin{array}{l}258-1-5,46-48 \\
258-3-1,93-95 \\
258-4-1,134-136\end{array}$ & $\begin{array}{r}6.5 \\
48.4 \\
86.8\end{array}$ & $\begin{array}{c}\text { Unit 1 } \\
\text { Sponge-, micarb-, } \\
\text { and foram-bearing } \\
\text { coccolith ooze }\end{array}$ & $\begin{array}{c}\text { Upper } \\
\text { Miocene } \\
\text { through } \\
\text { Quaternary } \\
\end{array}$ & $\begin{array}{l}\text { Arag. } \\
\text { Quar. }\end{array}$ & & $\begin{array}{l}\text { Quar. } \\
\text { Quar. } \\
\text { Quar. }\end{array}$ & $\begin{array}{l}\mathrm{K}-\mathrm{Fe} . \\
\mathrm{K}-\mathrm{Fe} . \\
\mathrm{K}-\mathrm{Fe} .\end{array}$ & $\begin{array}{l}\text { Mica } \\
\text { Mica } \\
\text { Kaol. }\end{array}$ & $\begin{array}{l}\text { Kaol. } \\
\text { Kaol. } \\
\text { Mont. }\end{array}$ & $\begin{array}{l}\text { Mont. } \\
\text { Mica } \\
\text { Kaol. }\end{array}$ & $\begin{array}{l}\text { Mica } \\
\text { Mont. } \\
\text { Mica }\end{array}$ \\
\hline $\begin{array}{l}258-6-5,120-122 \\
258-10-2,60-62\end{array}$ & $\begin{array}{l}149.7 \\
201.6\end{array}$ & $\begin{array}{c}\text { Unit } 2 \mathrm{~A} \\
\text { Foram and micarb- } \\
\text { bearing chalks }\end{array}$ & $\begin{array}{c}\text { Coniacian } \\
\text { and Santonian }\end{array}$ & $\begin{array}{l}\text { Mont. } \\
\text { Mont. }\end{array}$ & Cris. & $\begin{array}{l}\text { Quar. } \\
\text { Mont. }\end{array}$ & $\begin{array}{l}\text { Bari. } \\
\text { Cris. }\end{array}$ & $\begin{array}{l}\text { Mica } \\
\text { Bari. }\end{array}$ & $\begin{array}{l}\text { Cris. } \\
\text { Cris. }\end{array}$ & $\begin{array}{l}\text { Mont. } \\
\text { Mont. }\end{array}$ & Bari. \\
\hline $\begin{array}{l}258-12-4,130-132 \\
258-14-1,4-5\end{array}$ & $\begin{array}{l}240.3 \\
263.0\end{array}$ & $\begin{array}{c}\text { Unit 2B } \\
\begin{array}{c}\text { Coccolith micarb } \\
\text { chalk }\end{array}\end{array}$ & $\begin{array}{c}\text { Cenomanian } \\
\text { Turonian } \\
\text { and Coniacian }\end{array}$ & $\begin{array}{l}\text { Mont. } \\
\text { Clin. }\end{array}$ & $\begin{array}{l}\text { Calc. } \\
\text { Mont. }\end{array}$ & $\begin{array}{l}\text { Cris. } \\
\text { Cris. }\end{array}$ & $\begin{array}{l}\text { Mont. } \\
\text { Clin. }\end{array}$ & Bari. & $\begin{array}{l}\text { Cris. } \\
\text { Cris. }\end{array}$ & $\begin{array}{l}\text { Mont. } \\
\text { Mont. }\end{array}$ & \\
\hline $\begin{array}{l}258-14-1,54-55 \\
258-15-2,121-123\end{array}$ & $\begin{array}{l}263.5 \\
284.7 \\
\end{array}$ & $\begin{array}{c}\text { Unit } 3 \\
\text { Detrital clays } \\
\end{array}$ & $\begin{array}{c}\text { Late } \\
\text { Albian } \\
\end{array}$ & $\begin{array}{ll}\text { Cris. } & \text { Clin. } \\
\text { Mont. } & \text { Cris. } \\
\end{array}$ & Mont. & $\begin{array}{l}\text { Clin. } \\
\text { Clin. }\end{array}$ & $\begin{array}{l}\text { Cris. } \\
\text { Mont. }\end{array}$ & $\begin{array}{l}\text { Bari. } \\
\text { Kaol. }\end{array}$ & $\begin{array}{l}\text { Cris. } \\
\text { Mont. }\end{array}$ & $\begin{array}{l}\text { Mont. } \\
\text { Kaol. }\end{array}$ & Quar. \\
\hline $\begin{array}{l}258-16-5,114-116 \\
258-17-5,135-137 \\
258-18-2,103-105 \\
258-21-1,16-18 \\
258-22-5,70-72 \\
258-23-2,92-94\end{array}$ & $\begin{array}{l}308.1 \\
327.4 \\
341.5 \\
405.7 \\
441.7 \\
474.4 \\
\end{array}$ & $\begin{array}{l}\text { Unit } 4 \\
\text { Ferruginous } \\
\text { detrital } \\
\text { clays }\end{array}$ & $\begin{array}{l}\text { Middle and } \\
\text { late Albian } \\
\text { and indet. } \\
\text { Cretaceous }\end{array}$ & $\begin{array}{ll}\text { Mont. } & \text { Calc. } \\
\text { Mont. } & \text { Cris. } \\
\text { Cris. } & \text { Mont. } \\
\text { Cris. } & \text { Mont. } \\
\text { Mont. } & \text { Quar. } \\
\text { Mont. } & \text { Kaol. } \\
\end{array}$ & $\begin{array}{l}\text { Kaol. } \\
\text { Calc. } \\
\text { Calc. } \\
\text { Quar. }\end{array}$ & $\begin{array}{l}\text { Mont. } \\
\text { Mont. } \\
\text { Cris. } \\
\text { Cris. } \\
\text { Quar. } \\
\text { Mont. }\end{array}$ & $\begin{array}{l}\text { Cris. } \\
\text { Cris. } \\
\text { Quar. } \\
\text { Quar. } \\
\text { Mont. } \\
\text { Kaol. }\end{array}$ & $\begin{array}{l}\text { Quar. } \\
\text { Mica } \\
\text { Mont. } \\
\text { Mica } \\
\text { Mica }\end{array}$ & $\begin{array}{l}\text { Mont. } \\
\text { Cris. } \\
\text { Cris. } \\
\text { Cris. } \\
\text { Quar. } \\
\text { Mont. }\end{array}$ & $\begin{array}{l}\text { Cris. } \\
\text { Mont. } \\
\text { Mont. } \\
\text { Mica } \\
\text { Mont. } \\
\text { Kaol. }\end{array}$ & $\begin{array}{l}\text { Mica } \\
\text { Quar. } \\
\text { Quar. } \\
\text { Kaol. } \\
\text { Quar. }\end{array}$ \\
\hline $\begin{array}{l}258-24-5,53-55 \\
258-25-2,88-90\end{array}$ & $\begin{array}{l}516.5 \\
521.9\end{array}$ & $\begin{array}{l}\text { Unit } 5 \\
\text { Glauconite de- } \\
\text { trital silty clay }\end{array}$ & $\begin{array}{l}\text { Indet. } \\
\text { Cretaceous }\end{array}$ & $\begin{array}{l}\text { Mont. } \\
\text { K-Fe. }\end{array}$ & Mont. & $\begin{array}{l}\text { Mont. } \\
\text { K-Fe. }\end{array}$ & $\begin{array}{l}\text { K-Fe. } \\
\text { Magn. }\end{array}$ & $\begin{array}{l}\text { Pyri. } \\
\text { Hema. }\end{array}$ & $\begin{array}{l}\text { Mont. } \\
\text { Kaol. }\end{array}$ & $\begin{array}{l}\text { Kaol. } \\
\text { Mont. }\end{array}$ & $\begin{array}{l}\text { Mica } \\
\text { Hema. }\end{array}$ \\
\hline
\end{tabular}


TABLE 10

Results of X-Ray Diffraction Analysis, Hole 250

\begin{tabular}{|c|c|c|c|c|c|c|c|c|c|c|c|c|c|}
\hline Core & $\begin{array}{c}\text { Cored } \\
\text { Interval } \\
\text { Below Sea } \\
\text { Floor }(\mathrm{m})\end{array}$ & $\begin{array}{l}\text { Sample Depth } \\
\text { Below Sea } \\
\text { Floor }(\mathrm{m})\end{array}$ & 巡 & 客 & 远 & 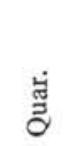 & 㭊 & $\frac{\text { gी }}{2}$ & $\begin{array}{l}\dot{0} \\
\ddot{g}\end{array}$ & $\stackrel{\mathscr{g}}{\Sigma}$ & $\stackrel{\dot{\Xi}}{\text { Ud }}$ & $\dot{\Xi}$ & 菅 \\
\hline \multicolumn{14}{|c|}{ Bulk Samples } \\
\hline \multirow[t]{3}{*}{1} & \multirow{3}{*}{$0.0-9.0$} & 0.9 & 84.6 & 75.9 & - & 16.0 & 7.5 & 5.8 & 7.8 & 19.1 & & 43.8 & - \\
\hline & & 5.5 & 80.7 & 69.8 & 48.3 & 12.8 & 4.1 & 5.7 & 7.2 & 9.8 & & 12.2 & - \\
\hline & & 7.0 & 85.8 & 77.7 & - & 25.0 & 7.0 & 8.0 & 13.9 & 20.1 & & 25.2 & 0.8 \\
\hline 2 & $9.0-18.5$ & 17.9 & 85.5 & 77.3 & 15.6 & 22.0 & 6.5 & 8.1 & 9.9 & 18.4 & & 18.4 & 1.1 \\
\hline \multicolumn{14}{|c|}{ 2-20 $\mu$ Fraction } \\
\hline \multirow[t]{3}{*}{1} & \multirow[t]{3}{*}{$0.0-9.0$} & 0.9 & 75.9 & 62.3 & & 22.5 & 15.3 & 13.6 & 6.9 & 29.6 & - & 12.2 & - \\
\hline & & 5.5 & 72.5 & 57.0 & & 33.1 & 10.9 & 18.8 & 10.2 & 24.2 & 1.5 & - & 1.3 \\
\hline & & 7.0 & 70.6 & 54.1 & & 29.1 & 11.1 & 14.4 & 8.4 & 28.2 & 1.7 & 5.8 & 1.3 \\
\hline 2 & $9.0-18.5$ & 17.9 & 72.1 & 56.3 & & 36.6 & 13.5 & 18.7 & 6.2 & 22.6 & 1.3 & - & 1.1 \\
\hline \multicolumn{14}{|c|}{$<2 \mu$ Fraction } \\
\hline \multirow[t]{3}{*}{1} & \multirow[t]{3}{*}{$0.0-9.0$} & 0.9 & 83.4 & 74.0 & & 5.2 & - & - & 8.2 & 13.2 & & 73.4 & - \\
\hline & & 5.5 & 85.6 & 77.5 & & 14.6 & - & 6.6 & 15.3 & 19.1 & & 43.3 & 1.0 \\
\hline & & 7.0 & 86.6 & 79.0 & & 13.2 & 5.7 & 6.6 & 14.8 & 13.6 & & 45.2 & 1.0 \\
\hline 2 & $9.0-18.5$ & 17.9 & 87.5 & 80.5 & & 16.3 & 4.8 & 5.9 & 11.8 & 16.8 & & 43.6 & 0.7 \\
\hline
\end{tabular}




\begin{tabular}{|c|c|c|c|c|c|c|c|c|c|c|c|c|c|c|c|c|c|c|c|c|c|}
\hline Core & $\begin{array}{c}\text { Cored } \\
\text { Interval } \\
\text { Below Sea } \\
\text { Floor (m) }\end{array}$ & $\begin{array}{l}\text { Sample Depth } \\
\text { Below Sea } \\
\text { Floor }(\mathrm{m})\end{array}$ & 范 & 客 & లँ & 융 & : & 嵌 & 离 & 㭊 & 茍 & 远 & $\stackrel{\Xi}{\Sigma}$ & 엵 & $\stackrel{\vec{E}}{\Sigma}$ & ฌ્ّ & 远 & 志 & $\dot{5}$ & :0 & 㧭 \\
\hline \multicolumn{22}{|c|}{ Bulk Samples } \\
\hline \multirow[t]{2}{*}{1} & $54.5-64.0$ & 56.3 & 84.5 & 75.9 & 22.2 & - & - & 17.1 & - & 4.1 & 7.5 & 10.5 & 18.9 & - & 19.0 & - & - & - & - & 0.6 & - \\
\hline & & 57.8 & 85.3 & 77.0 & - & - & - & 23.4 & - & 3.3 & 6.5 & 6.5 & 24.4 & 2.3 & 24.5 & 8.4 & - & - & - & 0.7 & - \\
\hline 3 & $73.5-83.0$ & 82.2 & 78.2 & 66.0 & 42.0 & - & - & 10.2 & - & 4.0 & 4.4 & 10.4 & 11.6 & - & 17.5 & - & - & - & - & & - \\
\hline 4 & $111.5-121.0$ & 117.4 & 85.6 & 77.5 & 10.2 & 0.8 & - & 19.5 & - & 4.2 & 6.7 & 12.7 & 21.9 & - & 24.0 & - & - & - & - & - & - \\
\hline 6 & $187.5-197.0$ & 191.4 & 85.6 & 77.5 & - & - & - & 23.4 & - & - & 11.8 & 10.5 & 31.5 & - & 22.6 & - & - & - & - & - & - \\
\hline \multirow[t]{2}{*}{7} & $235.0-243.5$ & 235.1 & 86.4 & 78.7 & - & - & - & 21.0 & - & 10.7 & 7.9 & 11.1 & 24.7 & - & 24.7 & - & - & - & - & - & - \\
\hline & & 242.0 & 83.7 & 74.5 & 6.0 & - & 4.4 & 19.5 & - & 7.8 & 6.4 & 10.5 & 24.5 & - & 20.9 & - & - & - & - & - & - \\
\hline 8 & $292.0-301.5$ & 292.3 & 83.9 & 74.8 & - & - & - & 20.6 & - & 6.6 & 9.1 & 11.0 & 26.5 & - & 26.2 & - & - & - & - & - & - \\
\hline 9 & $349.0-358.5$ & 351.9 & 84.4 & 75.7 & - & - & - & 23.6 & - & 7.5 & 7.1 & 11.9 & 23.3 & - & 26.6 & - & - & - & - & - & - \\
\hline 10 & $406.0-415.5$ & 407.6 & 86.8 & 79.3 & - & - & - & 26.7 & - & 7.8 & 8.5 & 10.0 & 30.2 & - & 16.9 & - & - & - & - & - & - \\
\hline \multirow[t]{2}{*}{11} & $463.0-472.5$ & 463.3 & 84.0 & 75.0 & - & - & - & 33.0 & - & 5.7 & 8.1 & 1.7 & 26.0 & 3.2 & 22.3 & - & - & - & - & - & - \\
\hline & & 470.2 & 83.8 & 74.6 & - & - & - & 33.4 & - & 7.6 & 10.0 & 2.1 & 26.5 & 3.9 & 16.5 & - & - & - & - & - & - \\
\hline \multirow[t]{2}{*}{13} & $567.5-577.0$ & 568.3 & 84.1 & 75.2 & - & - & - & 29.1 & - & 6.1 & 10.9 & 2.7 & 25.8 & 2.1 & 23.3 & - & - & - & - & - & - \\
\hline & & 568.8 & 84.7 & 76.2 & - & - & - & 32.2 & - & 6.9 & 11.4 & 1.7 & 31.8 & 2.6 & 13.4 & - & - & - & - & - & - \\
\hline 14 & $605.5-615.0$ & 607.2 & 83.8 & 74.7 & - & - & - & 22.6 & - & 8.0 & 3.1 & 7.1 & 22.5 & 3.1 & 33.6 & - & - & - & - & - & - \\
\hline 15 & $624.5-634.0$ & 626.9 & 84.1 & 75.2 & - & - & - & 22.3 & - & 16.2 & 10.8 & 8.1 & 21.2 & - & 21.5 & - & - & - & - & - & - \\
\hline 17 & $643.5-653.0$ & 646.1 & 87.1 & 79.8 & - & - & - & 24.4 & - & 6.8 & 8.9 & 6.2 & 18.4 & - & 18.4 & 17.0 & - & - & - & - & - \\
\hline 19 & $662.5-672.0$ & 664.3 & 87.3 & 80.2 & - & - & - & 19.0 & - & 6.5 & 6.2 & 2.2 & 23.0 & 1.2 & 13.6 & 28.3 & - & - & - & - & - \\
\hline 21 & $681.5-691.0$ & 684.0 & 83.0 & 73.5 & - & - & - & 18.9 & - & 3.5 & 3.7 & - & 9.3 & - & 29.3 & 35.3 & - & - & - & - & - \\
\hline 23 & $700.5-710.0$ & 701.5 & 90.6 & 85.3 & - & - & - & 5.1 & 69.6 & - & - & - & - & - & 4.2 & 7.3 & 13.8 & - & - & - & - \\
\hline 24 & $710.0-719.5$ & 712.8 & 86.0 & 78.1 & - & - & - & 14.9 & - & 5.9 & 3.8 & - & 11.4 & - & 30.3 & 30.8 & - & 3.0 & - & - & - \\
\hline 25 & $719.5-729.0$ & 719.7 & 89.9 & 84.2 & - & - & - & 19.0 & - & 6.6 & 3.8 & - & 5.2 & - & 21.3 & 44.1 & - & - & - & - & - \\
\hline \multicolumn{22}{|c|}{ 2-20 $\mu$ Fraction } \\
\hline \multirow[t]{2}{*}{1} & $54.5-64.0$ & 56.3 & 71.7 & 55.7 & - & - & - & 37.0 & - & 12.2 & 17.7 & 9.9 & 22.6 & - & - & - & - & - & - & 0.6 & - \\
\hline & & 57.8 & 69.3 & 52.0 & - & - & - & 32.8 & - & 12.9 & 16.5 & 9.1 & 26.1 & 1.3 & - & - & - & - & - & 1.3 & - \\
\hline 3 & $73.5-83.0$ & 82.2 & 72.2 & 56.5 & - & - & - & 29.7 & - & 15.5 & 14.7 & 16.7 & 21.0 & - & - & - & - & - & 1.6 & 0.7 & - \\
\hline 4 & $111.5-121.0$ & 117.4 & 70.7 & 54.3 & - & - & - & 34.2 & - & 14.0 & 15.6 & 11.4 & 22.6 & 0.7 & - & - & - & - & 0.9 & 0.6 & - \\
\hline 6 & $187.5-197.0$ & 191.4 & 64.8 & 45.1 & - & - & - & 34.8 & - & 12.7 & 22.3 & 2.8 & 25.9 & 1.4 & - & - & - & - & - & - & - \\
\hline \multirow[t]{2}{*}{7} & $235.0-243.5$ & 235.1 & 66.5 & 47.7 & - & - & - & 34.2 & - & 13.0 & 18.4 & 4.6 & 27.3 & 1.2 & - & - & - & - & 1.3 & - & - \\
\hline & & 242.0 & 68.8 & 51.3 & - & - & - & 34.1 & - & 14.7 & 17.2 & 6.9 & 26.4 & 0.7 & - & - & - & - & - & - & - \\
\hline 8 & $292.0-301.5$ & 292.3 & 66.7 & 47.9 & - & - & - & 37.7 & - & 13.4 & 18.3 & 4.8 & 24.4 & 1.4 & - & - & - & - & - & - & - \\
\hline 9 & $349.0-358.5$ & 351.9 & 66.8 & 48.1 & - & - & - & 38.2 & - & 13.4 & 18.1 & 4.0 & 25.1 & 1.2 & - & - & - & - & - & - & - \\
\hline 10 & $406.0-415.5$ & 407.6 & 64.1 & 44.0 & - & - & - & 42.7 & - & 12.6 & 18.3 & 1.5 & 23.8 & 1.1 & - & - & - & - & - & - & - \\
\hline
\end{tabular}




\begin{tabular}{|c|c|c|c|c|c|c|c|c|c|c|c|c|c|c|c|c|c|c|c|c|c|}
\hline \multirow[t]{2}{*}{11} & $463.0-472.5$ & 463.3 & 61.2 & 39.4 & - & - & - & 45.8 & - & 10.8 & 19.2 & - & 22.8 & 1.3 & - & - & - & - & - & - & - \\
\hline & & 470.2 & 63.5 & 42.9 & - & - & - & 49.1 & - & 11.0 & 20.5 & 1.0 & 17.5 & 0.8 & - & - & - & - & - & - & - \\
\hline \multirow{2}{*}{13} & $567.5-577.0$ & 568.3 & 61.8 & 40.3 & - & - & - & 48.3 & - & 13.7 & 21.2 & 0.6 & 15.6 & 0.6 & - & - & - & - & - & - & - \\
\hline & & 568.8 & 57.8 & 34.1 & - & - & - & 50.5 & - & 11.3 & 23.5 & - & 13.4 & 1.2 & - & - & - & - & - & - & - \\
\hline 14 & $605.5-615.0$ & 607.2 & 59.0 & 35.9 & - & - & - & 52.1 & - & 14.6 & 16.7 & 0.8 & 14.9 & 0.9 & - & - & - & - & - & - & - \\
\hline 15 & $624.5-634.0$ & 626.9 & 63.9 & 43.6 & - & - & - & 35.2 & - & 22.7 & 17.2 & 2.5 & 22.5 & - & - & - & - & - & - & - & - \\
\hline 17 & $643.5-653.0$ & 646.1 & 64.9 & 45.2 & - & - & - & 42.1 & - & 13.9 & 19.7 & 2.8 & 20.4 & 1.0 & - & - & - & - & - & - & - \\
\hline 19 & $662.5-672.0$ & 664.3 & 67.4 & 49.1 & - & - & - & 37.6 & - & 19.9 & 20.8 & - & 19.3 & 2.4 & - & - & - & - & - & - & - \\
\hline 21 & $681.5-691.0$ & 684.0 & 62.1 & 40.8 & - & - & - & 45.6 & - & 13.1 & 17.8 & - & 15.1 & 1.8 & - & 6.6 & - & - & - & - & - \\
\hline 23 & $700.5-710.0$ & 701.5 & 87.4 & 80.4 & - & - & - & 4.7 & 72.2 & 1.7 & 2.3 & - & 1.3 & - & - & 4.5 & 13.3 & - & - & - & - \\
\hline 24 & $710.0-719.5$ & 712.8 & 75.0 & 60.9 & - & - & - & 31.4 & - & 9.2 & 14.6 & - & 24.8 & - & 9.8 & - & - & 10.3 & - & - & - \\
\hline 25 & $719.5-729.0$ & 719.7 & 76.5 & 63.2 & - & - & - & 33.2 & - & 20.1 & 15.8 & - & 28.0 & 3.0 & - & - & - & - & - & - & - \\
\hline
\end{tabular}

\begin{tabular}{|c|c|c|c|c|c|c|c|c|c|c|c|c|c|c|c|c|c|c|c|c|c|}
\hline \multicolumn{22}{|c|}{$<2 \mu$ Fraction } \\
\hline 1 & $54.5-64.0$ & 56.3 & 85.8 & 77.9 & - & - & - & 16.2 & - & 5.0 & 3.5 & 13.5 & 15.1 & - & 45.7 & - & - & - & - & 0.8 & - \\
\hline & & 57.8 & 85.1 & 76.7 & - & - & - & 17.7 & - & 6.0 & 4.7 & 13.1 & 14.4 & - & 36.7 & 7.4 & - & - & - & - & - \\
\hline 3 & $73.5-83.0$ & 82.2 & 86.0 & 78.2 & - & - & - & 12.5 & - & 3.3 & 3.8 & 13.2 & 11.5 & - & 55.7 & - & - & - & - & - & - \\
\hline 4 & $111.5-121.0$ & 117.4 & 86.5 & 78.8 & - & - & - & 14.6 & - & 3.7 & 5.4 & 13.0 & 12.2 & - & 48.0 & - & - & - & - & - & 3.1 \\
\hline 6 & $187.5-197.0$ & 191.4 & 87.8 & 81.0 & - & - & - & 15.7 & - & 6.6 & 7.2 & 8.2 & 17.6 & - & 38.8 & - & - & - & - & - & 5.9 \\
\hline \multirow[t]{2}{*}{7} & $235.0-243.5$ & 235.1 & 83.2 & 73.8 & - & - & - & 15.2 & - & 7.1 & 4.7 & 10.9 & 29.5 & - & 25.4 & - & - & - & - & - & 7.3 \\
\hline & & 242.0 & 89.0 & 82.8 & - & - & - & 15.3 & - & 4.3 & 2.8 & 13.2 & 18.7 & - & 45.7 & - & - & - & - & - & - \\
\hline 8 & $292.0-301.5$ & 292.3 & 85.5 & 77.4 & - & - & - & 15.1 & - & 6.2 & 2.7 & 10.7 & 20.0 & - & 43.6 & - & - & - & - & - & 1.7 \\
\hline 9 & $349.0-358.5$ & 351.9 & 83.5 & 74.3 & - & - & - & 17.5 & - & 7.9 & 7.4 & 10.1 & 23.9 & - & 29.3 & - & - & - & - & - & 3.9 \\
\hline 10 & $406.0-415.5$ & 407.6 & 85.5 & 77.4 & - & - & - & 16.5 & - & 7.4 & 4.1 & 7.1 & 37.0 & - & 24.4 & - & - & - & - & - & 3.5 \\
\hline \multirow[t]{2}{*}{11} & $463.0-472.5$ & 463.3 & 84.3 & 75.4 & - & - & - & 20.4 & - & 5.9 & 5.3 & 7.6 & 24.6 & - & 34.1 & - & - & - & - & - & 2.1 \\
\hline & & 470.2 & 86.0 & 78.1 & - & - & - & 20.9 & - & 5.8 & 4.2 & 7.3 & 24.9 & - & 31.7 & - & - & - & - & - & 5.2 \\
\hline \multirow[t]{2}{*}{13} & $567.5-577.0$ & 568.3 & 85.7 & 77.6 & - & - & - & 19.1 & - & 5.8 & 4.7 & 2.6 & 25.2 & - & 31.2 & - & - & - & - & - & 9.2 \\
\hline & & 568.8 & 86.6 & 79.0 & - & - & - & 27.8 & - & 5.1 & 6.4 & 6.4 & 27.2 & - & 19.2 & - & - & - & - & - & 7.8 \\
\hline 14 & $605.5-615.0$ & 607.2 & 88.0 & 81.3 & - & - & - & 22.6 & - & 8.0 & 3.1 & 7.1 & 22.5 & 3.1 & 33.6 & - & - & - & - & - & - \\
\hline 15 & $624.5-634.0$ & 626.9 & 87.4 & 80.3 & - & - & - & 11.5 & - & 6.5 & - & 8.4 & 22.5 & - & 41.7 & - & - & - & - & - & 9.4 \\
\hline 17 & $643.5-653.0$ & 646.1 & 87.9 & 81.1 & - & - & - & 16.9 & - & 5.5 & 4.3 & 7.7 & 20.0 & - & 28.5 & 17.1 & - & - & - & - & - \\
\hline 19 & $662.5-672.0$ & 664.3 & 88.9 & 82.6 & - & - & - & 9.5 & - & 5.7 & 2.4 & 2.3 & 23.5 & 0.8 & 33.2 & 22.7 & - & - & - & - & - \\
\hline 21 & 681.5-691.0 & 684.0 & 85.8 & 77.8 & - & - & - & 18.0 & - & - & - & - & 12.8 & - & 36.2 & 33.0 & - & - & - & - & - \\
\hline 23 & $700.5-710.0$ & 701.5 & 94.0 & 90.7 & - & - & - & 1.5 & 73.4 & - & - & - & - & - & 5.7 & 5.1 & 12.6 & - & - & - & 1.7 \\
\hline 24 & $710.0-719.5$ & 712.8 & 86.7 & 79.2 & - & - & - & 9.4 & - & - & - & - & 8.0 & - & 52.9 & 29.8 & - & - & - & - & - \\
\hline 25 & $719.5-729.0$ & 719.7 & 88.1 & 81.3 & - & - & - & 8.5 & - & 2.5 & - & - & 9.5 & - & 50.6 & 29.0 & - & - & - & - & - \\
\hline
\end{tabular}


TABLE 12

Results of X-Ray Diffraction Analysis, Hole 250A

\begin{tabular}{|c|c|c|c|c|c|c|c|c|c|c|c|c|}
\hline Core & $\begin{array}{c}\text { Cored } \\
\text { Interval } \\
\text { Below Sea } \\
\text { Floor }(\mathrm{m})\end{array}$ & $\begin{array}{l}\text { Sample Depth } \\
\text { Below Sea } \\
\text { Floor (m) }\end{array}$ & 巡 & 客 & లુ & 荡 & $\frac{\dot{0}}{\frac{1}{1}}$ & $\stackrel{\text { gी }}{a}$ & ठ் & $\stackrel{\text { 巳゙ }}{\Sigma}$ & 을 & 茂 \\
\hline \multicolumn{13}{|c|}{ Bulk Samples } \\
\hline 1 & $0.0-2.0$ & 0.9 & 54.1 & 28.2 & 95.8 & 1.7 & - & 1.1 & - & 1.4 & - & - \\
\hline \multirow[t]{2}{*}{3} & $11.5-21.0$ & 12.8 & 51.5 & 24.3 & 99.6 & 0.4 & - & - & - & - & - & - \\
\hline & & 14.8 & 57.1 & 33.0 & 96.8 & 1.8 & - & - & - & 1.4 & - & - \\
\hline 5 & $30.5-40.0$ & 37.2 & 51.2 & 23.8 & 98.4 & 0.5 & - & - & - & 1.1 & - & - \\
\hline 7 & $49.5-59.0$ & 57.5 & 52.2 & 25.3 & 98.7 & 1.3 & - & - & - & - & - & - \\
\hline 10 & $78.0-87.5$ & 84.2 & 62.9 & 42.0 & 98.2 & 1.8 & - & - & - & - & - & - \\
\hline \multicolumn{13}{|c|}{ 2-20 $\mu$ Fraction } \\
\hline 1 & $0.0-2.0$ & 0.9 & 68.8 & 51.3 & - & 33.8 & 11.0 & 25.9 & - & 25.4 & 3.9 & - \\
\hline \multirow[t]{2}{*}{3} & $11.5-21.0$ & 12.8 & 72.0 & 56.3 & - & 46.9 & 10.0 & 22.0 & - & 19.2 & 1.9 & - \\
\hline & & 14.8 & 75.4 & 61.6 & - & 48.3 & 8.4 & 25.8 & 2.9 & 13.1 & 1.4 & - \\
\hline 5 & $30.5-40.0$ & 37.2 & 77.6 & 65.0 & - & 44.0 & 9.1 & 23.8 & - & 20.6 & 2.5 & - \\
\hline 7 & $49.5-59.0$ & 57.5 & 77.8 & 65.4 & - & 42.5 & 10.1 & 26.0 & - & 19.6 & 1.8 & - \\
\hline 10 & $78.0-87.5$ & 84.2 & 71.8 & 55.9 & - & 42.8 & 9.8 & 25.5 & - & 20.0 & 1.9 & - \\
\hline \multicolumn{13}{|c|}{$<2 \mu$ Fraction } \\
\hline 1 & $0.0-2.0$ & 0.9 & 95.2 & 92.5 & - & 19.1 & - & 14.7 & 10.1 & 21.2 & - & 34.9 \\
\hline \multirow[t]{2}{*}{3} & $11.5-21.0$ & 12.8 & 88.5 & 82.0 & - & 9.9 & 3.7 & 4.4 & 7.5 & 10.3 & - & 64.3 \\
\hline & & 14.8 & 92.9 & 88.9 & - & 22.2 & - & 11.0 & 8.0 & 15.7 & - & 43.1 \\
\hline 5 & $30.5-40.0$ & 37.2 & 94.5 & 91.5 & - & 13.1 & - & 11.8 & 10.5 & 25.3 & - & 39.3 \\
\hline 7 & $49.5-59.0$ & 57.5 & 88.2 & 81.6 & - & 16.6 & - & 8.3 & 8.3 & 15.0 & - & 51.8 \\
\hline 10 & $78.0-87.5$ & 84.2 & 93.7 & 90.1 & - & 23.5 & 5.3 & 12.2 & 9.8 & 23.5 & - & 25.6 \\
\hline
\end{tabular}


TABLE 13

Results of X-Ray Diffraction Analysis, Hole 251A

\begin{tabular}{|c|c|c|c|c|c|c|c|c|c|c|c|c|c|c|c|c|}
\hline Core & $\begin{array}{l}\text { Cored } \\
\text { Interval } \\
\text { Below Sea } \\
\text { Floor }(\mathrm{m})\end{array}$ & $\begin{array}{l}\text { Sample Depth } \\
\text { Below Sea } \\
\text { Floor }(\mathrm{m})\end{array}$ & 迅 & 岁 & गु & $\begin{array}{l}\text { a } \\
\text { p }\end{array}$ & 荡 & 这 & 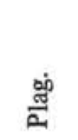 & $\begin{array}{l}\dot{0} \\
\stackrel{\Xi}{ }\end{array}$ & $\stackrel{\Xi}{\check{2}}$ & తิ & $\stackrel{\stackrel{\Xi}{\Xi}}{\stackrel{\Sigma}{\Sigma}}$ & त्तु & 完 & 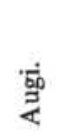 \\
\hline \multicolumn{17}{|c|}{ Bulk Samples } \\
\hline 1 & $78.0-87.5$ & 85.8 & 50.7 & 22.9 & 99.1 & - & 0.9 & - & - & - & - & - & - & - & - & - \\
\hline 4 & $106.5-116.0$ & 114.2 & 49.9 & 21.7 & 99.0 & - & 1.0 & - & - & - & - & - & - & - & - & - \\
\hline 6 & $125.5-135.0$ & 133.2 & 53.8 & 27.8 & 99.4 & - & 0.6 & - & - & - & - & - & - & - & - & - \\
\hline 9 & $154.0-163.5$ & 158.7 & 52.9 & 26.4 & 99.0 & - & 1.0 & - & - & - & - & - & - & - & - & - \\
\hline 12 & $220.5-230.0$ & 228.2 & 51.2 & 23.7 & 98.9 & - & 1.1 & - & - & - & - & - & - & - & - & - \\
\hline 15 & $306.0-315.5$ & 309.3 & 51.2 & 23.8 & 99.0 & - & 1.0 & - & - & - & - & - & - & - & - & - \\
\hline 18 & $372.5-382.0$ & 373.1 & 49.8 & 21.6 & 97.1 & - & 1.0 & - & - & - & 1.9 & - & - & - & - & - \\
\hline 20 & $391.5-401.0$ & 399.3 & 56.6 & 32.2 & 92.9 & - & 2.1 & - & - & - & 2.9 & 2.1 & - & - & - & - \\
\hline 22 & $410.5-420.0$ & 414.5 & 54.0 & 28.1 & 98.8 & - & 1.2 & - & - & - & - & - & - & - & - & - \\
\hline 24 & $429.5-439.0$ & 435.3 & 61.3 & 39.6 & 88.8 & - & 4.2 & 1.2 & 1.5 & - & 4.2 & - & - & - & - & - \\
\hline \multirow[t]{2}{*}{26} & $448.5-458.0$ & 453.0 & 54.2 & 28.4 & 95.6 & - & 2.0 & - & - & - & 2.4 & - & - & - & - & - \\
\hline & & 454.2 & 56.3 & 31.8 & 93.2 & - & 3.3 & - & - & - & 3.5 & - & - & - & - & - \\
\hline 29 & $477.0-486.5$ & 478.7 & 47.4 & 17.8 & 82.9 & 13.2 & - & - & - & - & - & - & - & - & - & 3.9 \\
\hline \multicolumn{17}{|c|}{ 2-20 $\mu$ Fraction } \\
\hline 1 & $78.0-87.5$ & 85.8 & 61.9 & 40.4 & - & - & 35.6 & 9.2 & 26.4 & - & 25.2 & 3.5 & - & - & - & - \\
\hline 4 & $106.5-116.0$ & 114.2 & 75.3 & 61.5 & - & - & 43.8 & 9.1 & 23.7 & - & 21.3 & 2.1 & - & - & - & - \\
\hline 6 & $125.5-135.0$ & 133.2 & 77.9 & 65.5 & - & - & 39.4 & 11.2 & 21.2 & - & 19.2 & 1.7 & 7.3 & - & - & - \\
\hline 9 & $154.0-163.5$ & 158.7 & 72.5 & 57.0 & - & - & 35.0 & 13.5 & 25.5 & - & 22.8 & 2.1 & - & - & 1.2 & - \\
\hline 12 & $220.5-230.0$ & 228.2 & 76.9 & 63.9 & - & - & 39.2 & 10.1 & 21.3 & 1.8 & 25.4 & 1.1 & - & - & 1.2 & - \\
\hline 15 & $306.0-315.5$ & 309.3 & 77.8 & 65.2 & - & - & 35.3 & 7.8 & 33.8 & 4.0 & 19.2 & - & - & - & - & - \\
\hline 18 & $372-5-382.0$ & 373.1 & 59.2 & 36.2 & - & - & 45.0 & 14.9 & 15.2 & 4.1 & 20.8 & - & - & - & - & - \\
\hline 20 & $391.5-401.0$ & 399.3 & 70.6 & 54.1 & - & - & 42.1 & 13.4 & 14.4 & - & 23.0 & 1.3 & 5.7 & - & - & - \\
\hline 22 & $410.5-420.0$ & 414.5 & 66.8 & 48.1 & - & - & 47.6 & 9.4 & 18.5 & - & 22.4 & 2.0 & - & - & - & - \\
\hline 24 & $429.5-439.0$ & 435.3 & 72.4 & 56.8 & - & - & 42.1 & 12.3 & 19.2 & 0.3 & 24.2 & 1.9 & - & - & - & - \\
\hline \multirow[t]{2}{*}{26} & $448.5-458.0$ & 453.0 & 66.8 & 48.2 & - & - & 40.1 & 12.7 & 19.3 & - & 25.6 & 2.3 & - & - & - & - \\
\hline & & 454.2 & 64.2 & 44.0 & - & - & 46.2 & 12.7 & 20.0 & - & 19.9 & 1.2 & - & - & - & - \\
\hline 29 & $477.0-486.5$ & 478.7 & 51.0 & 23.4 & - & 93.0 & - & - & - & - & - & - & - & - & - & 7.0 \\
\hline \multicolumn{17}{|c|}{$<2 \mu$ Fraction } \\
\hline 1 & $78.0-87.5$ & 85.8 & 91.3 & 86.4 & - & - & 22.0 & 10.5 & 5.4 & 11.9 & 25.5 & - & 24.7 & - & - & - \\
\hline 4 & $106.5-116.0$ & 114.2 & 90.6 & 85.3 & - & - & 12.1 & - & 9.8 & - & 36.8 & - & 41.3 & - & - & - \\
\hline 6 & $125.5-135.0$ & 133.2 & 90.9 & 85.8 & - & - & 11.7 & 3.3 & 6.8 & 7.9 & 26.3 & - & 44.0 & - & - & - \\
\hline 9 & $154.0-163.5$ & 158.7 & 93.9 & 90.4 & - & - & 18.3 & 7.7 & 8.5 & 11.5 & 24.8 & - & 29.3 & - & - & - \\
\hline 12 & $220.5-230.0$ & 228.2 & 93.0 & 89.1 & - & - & 14.8 & 10.5 & 5.8 & 8.8 & 27.0 & - & 33.1 & - & - & - \\
\hline 15 & $306.0-315.5$ & 309.3 & 87.0 & 79.8 & - & - & 9.0 & 5.5 & 4.2 & 5.3 & 19.2 & - & 56.9 & - & - & - \\
\hline 18 & $372.5-382.0$ & 373.1 & 93.4 & 89.7 & - & - & 12.1 & - & 5.7 & 8.3 & 29.5 & - & 44.3 & - & - & - \\
\hline 20 & $391.5-401.0$ & 399.3 & 91.6 & 86.8 & - & - & 12.4 & 6.4 & 2.5 & 5.0 & 27.5 & - & 46.2 & - & - & - \\
\hline 22 & $410.5-420.0$ & 414.5 & 93.0 & 89.0 & - & - & 14.9 & - & 4.2 & 7.2 & 29.5 & - & 44.2 & - & - & - \\
\hline 24 & $429.5-439.0$ & 435.3 & 89.2 & 83.2 & - & - & 13.5 & 2.1 & 4.9 & 6.4 & 28.3 & - & 44.7 & - & - & - \\
\hline \multirow[t]{2}{*}{26} & $448.5-458.0$ & 453.0 & 90.8 & 85.6 & - & - & 12.9 & - & 3.0 & 4.6 & 9.8 & - & 30.2 & 39.6 & - & - \\
\hline & & 454.2 & 91.5 & 86.8 & - & - & 21.4 & 9.7 & 3.9 & 7.0 & 39.4 & - & 18.7 & - & - & - \\
\hline 29 & $477.0-486.5$ & 478.7 & 63.6 & 43.1 & - & 5.8 & 0.8 & - & - & - & - & - & 15.8 & - & - & 77.6 \\
\hline
\end{tabular}

${ }^{\mathrm{a}}$ This mineral has been identified to be a garnet close in composition to grossularite. Diffraction peaks at 2.67A, 2.98A, and $1.59 \mathrm{~A}$, among others. An intensity factor of 2.49 was determined from the (420) peak of grossularite. 
TABLE 14

Results of X-Ray Diffraction Analysis, Site 252

\begin{tabular}{|c|c|c|c|c|c|c|c|c|c|c|c|c|c|c|c|}
\hline Core & $\begin{array}{c}\text { Cored } \\
\text { Interval } \\
\text { Below Sea } \\
\text { Floor }(\mathrm{m})\end{array}$ & $\begin{array}{l}\text { Sample Depth } \\
\text { Below Sea } \\
\text { Floor }(\mathrm{m})\end{array}$ & $\ddot{\mathscr{B}}$ & $\stackrel{\dot{S}}{\mathrm{E}}$ & 㟧 & 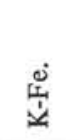 & $\frac{\stackrel{d 0}{a}}{a}$ & $\begin{array}{l}\dot{0} \\
\check{\check{\varpi}}\end{array}$ & $\stackrel{\Xi}{\Sigma}$ & 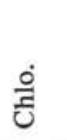 & 䒕 & 氶 & 兽 & 离 & 宓 \\
\hline \multicolumn{16}{|c|}{ Bulk Samples } \\
\hline \multirow[t]{2}{*}{2} & \multirow[t]{2}{*}{$0.0-9.5$} & 1.8 & 88.7 & 82.4 & 12.3 & 17.1 & 22.3 & 3.4 & 12.0 & - & 12.8 & - & 3.0 & - & 17.2 \\
\hline & & 3.7 & 88.8 & 82.5 & 13.7 & 12.2 & 20.4 & 3.0 & 9.8 & - & 14.6 & - & - & 1.7 & 24.5 \\
\hline 4 & $95.0-104.5$ & 103.7 & 90.4 & 84.9 & 13.4 & 13.7 & 18.1 & - & 16.7 & - & 17.4 & 1.1 & - & 0.9 & 18.5 \\
\hline 6 & $190.0-199.5$ & 194.2 & 89.3 & 83.2 & 11.2 & 4.0 & 21.5 & - & 8.6 & - & 12.3 & 2.2 & - & 3.6 & 36.7 \\
\hline 7 & $237.5-247.0$ & 240.4 & 88.2 & 81.5 & 13.2 & 5.1 & 19.9 & - & 8.6 & - & 20.5 & 1.8 & - & 2.5 & 28.4 \\
\hline \multicolumn{16}{|c|}{ 2-20 $\mu$ Fraction } \\
\hline \multirow[t]{2}{*}{2} & \multirow[t]{2}{*}{$0.0-9.5$} & 1.8 & 81.8 & 71.6 & 17.3 & 20.4 & 24.1 & - & 5.6 & - & - & 0.9 & 2.8 & - & 29.0 \\
\hline & & 3.7 & 78.9 & 67.0 & 15.6 & 14.2 & 20.7 & - & 3.8 & 0.9 & - & 1.0 & - & 13.2 & 30.7 \\
\hline 4 & $.95 .0-104.5$ & 103.7 & 86.1 & 78.3 & 20.8 & 9.2 & 24.2 & - & 7.4 & - & - & 1.5 & - & 1.8 & 35.1 \\
\hline 6 & $190.0-199.5$ & 194.2 & 80.8 & 69.9 & 10.0 & 4.7 & 22.7 & - & 5.8 & 2.3 & 8.2 & 2.1 & - & 2.1 & 41.9 \\
\hline 7 & $237.5-247.0$ & 240.4 & 83.8 & 74.7 & 15.0 & 7.0 & 24.3 & - & 10.9 & - & 8.9 & 1.7 & - & 1.4 & 30.8 \\
\hline \multicolumn{16}{|c|}{$<2 \mu$ Fraction } \\
\hline \multirow[t]{2}{*}{2} & \multirow[t]{2}{*}{$0.0-9.5$} & 1.8 & 91.5 & 86.6 & 11.8 & 7.0 & 16.7 & 3.7 & 15.0 & - & 40.0 & - & - & - & 5.8 \\
\hline & & 3.7 & 89.7 & 83.8 & 12.1 & 9.0 & 10.5 & 3.3 & 12.5 & - & 23.5 & - & - & 21.1 & 8.1 \\
\hline 4 & $95.0-104.5$ & 103.7 & 92.4 & 88.2 & 10.6 & 8.5 & 11.8 & 2.2 & 13.3 & 2.4 & 44.7 & - & - & - & 6.5 \\
\hline 6 & $190.0-199.5$ & 194.2 & 93.4 & 89.6 & 11.7 & 9.9 & 18.0 & - & 13.9 & - & 34.6 & - & - & 2.7 & 9.2 \\
\hline 7 & $237.5-247.0$ & 240.4 & 92.5 & 88.3 & 13.2 & 5.2 & 14.3 & - & 21.7 & - & 34.3 & - & - & 2.1 & 9.2 \\
\hline
\end{tabular}


TABLE 15

Results of X-Ray Diffraction Analysis, Site 253

\begin{tabular}{|c|c|c|c|c|c|c|c|c|c|c|c|c|c|c|c|c|c|c|c|c|c|c|c|c|c|c|c|c|c|}
\hline Core & $\begin{array}{c}\text { Cored } \\
\text { Interval } \\
\text { Below Sea } \\
\text { Floor }(\mathrm{m})\end{array}$ & $\begin{array}{c}\text { Sample Depth } \\
\text { Below Sea } \\
\text { Floor }(\mathrm{m}) \\
\end{array}$ & 氙 & 总 & 苞 & $\frac{0}{3}$ & $\stackrel{\circ}{\overline{5}}$ & 递 & है & $\frac{\dot{\sim}}{\dot{\Delta}}$ & $\frac{d \vec{b}}{2}$ & 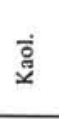 & $\frac{\pi}{2}$ & 总 & $\frac{\vec{c}}{2}$ & 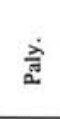 & 를 & 咅 & 菻 & 忘 & 仓ิ & 㟧 & 音 & 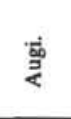 & 惡 & 苞 & ङे & 3 & $\stackrel{\infty}{\stackrel{m}{\zeta}}$ \\
\hline \multicolumn{30}{|c|}{ Bulk Sample } \\
\hline 1 & $0.0-9.0$ & 2.6 & 51.7 & 24.6 & 100.0 & - & - & - & - & - & - & - & - & - & - & - & - & - & - & - & - & - & - & - & - & - & - & - & - \\
\hline 5 & $37.5-47.0$ & 45.7 & 46.9 & 17.1 & 100.0 & - & - & - & - & - & - & - & - & - & - & - & - & - & - & - & - & - & - & - & - & - & - & - & - \\
\hline 7 & $56.5-66.0$ & 58.9 & 45.6 & 15.0 & 100.0 & - & - & - & - & - & - & - & - & - & - & - & - & - & - & - & - & - & - & - & - & - & - & - & - \\
\hline 9 & $75.5-85.0$ & 80.9 & 48.0 & 18.8 & 100.0 & - & - & - & - & - & - & - & - & - & - & - & - & - & - & - & - & - & - & - & - & - & - & - & - \\
\hline 11 & $94.5-104.0$ & 96.9 & 51.2 & 23.7 & 100.0 & - & - & - & - & - & - & - & - & - & - & - & - & - & - & - & - & - & - & - & - & - & - & - & - \\
\hline 13 & $113.5-123.0$ & 115.9 & 86.0 & 78.2 & 100.0 & - & - & - & - & - & - & - & - & - & - & - & - & - & - & - & - & - & - & - & - & - & & - & - \\
\hline 16 & $142.0-151.5$ & 150.9 & 56.1 & 31.3 & 99.3 & - & - & - & - & - & - & - & - & - & - & - & 0.7 & - & - & - & - & - & - & - & - & - & - & - & - \\
\hline 17 & $151.5-161.0$ & 154.1 & 90.1 & 84.6 & - & P & - & 5.4 & - & - & 27.1 & - & - & - & 56.7 & - & - & - & - & - & - & - & - & - & 10.9 & - & - & - & - \\
\hline \multirow[t]{2}{*}{18} & $161.0-170.5$ & 163.4 & 80.0 & 68.9 & 73.1 & $\mathbf{P}$ & - & 0.5 & - & - & 4.0 & - & - & - & 22.4 & - & - & - & - & - & - & - & - & - & - & - & - & - & - \\
\hline & & 165.6 & 89.1 & 83.0 & 37.2 & P & - & - & - & - & 8.6 & - & - & - & 33.7 & - & - & - & - & 1.3 & - & - & - & 19.2 & - & - & - & - & - \\
\hline 20 & $180.0-189.5$ & 182.5 & 70.2 & 53.5 & 85.8 & $T$ & - & - & - & - & 2.5 & - & - & - & 11.7 & - & - & - & - & - & - & - & - & - & - & - & - & - & - \\
\hline 23 & $208.5-218.0$ & 210.9 & 68.2 & 50.4 & 59.9 & $\mathrm{~T}$ & - & 0.6 & - & - & 5.3 & - & - & - & 20.4 & - & 0.8 & 13.1 & - & - & - & - & - & - & - & - & - & - & - \\
\hline 25 & $227.5-237.0$ & 229.9 & 75.5 & 61.8 & 41.3 & P & - & 0.5 & - & - & - & - & - & - & 48.4 & - & - & 9.8 & - & - & - & - & - & - & - & - & - & - & - \\
\hline 30 & $269.5-279.0$ & 270.6 & 68.9 & 51.5 & 80.7 & P & - & 0.5 & - & - & 4.3 & - & 2.3 & - & 3.6 & - & 7.5 & - & - & - & - & - & - & - & 1.1 & - & - & - & - \\
\hline 31 & $279.0-288.5$ & 281.6 & 74.3 & 59.9 & 37.8 & P & - & 1.4 & - & - & 11.5 & - & - & - & 30.8 & - & 18.5 & - & - & - & - & - & - & - & - & - & - & - & - \\
\hline 36 & $326.5-336.0$ & 327.8 & 78.7 & 66.8 & - & P & $T$ & - & - & - & 4.7 & - & - & - & 67.7 & - & 23.4 & - & 1.0 & - & - & - & - & - & 3.1 & - & $\mathrm{T}$ & $\mathrm{T}$ & - \\
\hline 38 & $345.5-355.0$ & 346.5 & 65.6 & 46.3 & 33.3 & P & - & - & - & - & - & - & - & - & 50.7 & - & 9.2 & - & - & - & - & - & - & - & 5.6 & 1.2 & - & $P$ & - \\
\hline 40 & $364.5-374.0$ & 366.5 & 66.6 & 47.9 & 22.9 & P & $P$ & - & - & - & 5.7 & - & - & - & 61.8 & - & 1.1 & - & 6.2 & - & - & - & - & - & 1.7 & 0.6 & - & - & - \\
\hline 42 & $383.5-393.0$ & 386.4 & 73.3 & 58.2 & 2.7 & P & $P$ & - & - & - & 3.9 & - & - & - & 78.7 & - & 12.7 & - & - & - & - & - & - & - & - & 2.0 & - & - & - \\
\hline 44 & $402.5-412.0$ & 404.1 & 74.3 & 59.8 & 27.7 & P & $\mathrm{T}$ & - & - & - & - & - & - & - & 71.7 & - & - & - & - & - & - & - & - & - & - & 0.6 & - & - & - \\
\hline 46 & $421.5-431.0$ & 424.0 & 73.8 & 59.1 & 36.2 & P & $P$ & - & - & - & - & - & - & - & 49.2 & - & 6.6 & - & 5.6 & - & - & - & - & - & - & 2.5 & - & - & - \\
\hline 48 & $440.5-450.0$ & 442.6 & 68.9 & 51.4 & 13.2 & P & $\mathrm{T}$ & - & - & - & - & - & - & - & 71.6 & - & - & - & 14.6 & - & - & - & - & - & - & 0.6 & - & - & - \\
\hline 49 & $450.0-459.5$ & 452.1 & 73.7 & 59.0 & - & $\mathrm{P}$ & $\mathrm{T}$ & - & - & - & - & - & - & - & 84.1 & - & 3.4 & - & 12.1 & - & - & - & - & - & - & 0.5 & - & - & - \\
\hline 51 & $469.0-478.5$ & 470.9 & 72.0 & 56.2 & 22.1 & P & $P$ & - & - & - & - & - & - & - & 64.0 & - & 7.8 & - & 4.1 & - & - & - & - & - & - & 1.9 & - & - & - \\
\hline 52 & $478.5-488.0$ & 481.3 & 66.3 & 47.4 & 9.5 & P & $P$ & 2.0 & - & - & 2.7 & - & - & - & 65.6 & - & - & - & 19.2 & - & - & - & - & - & - & 0.9 & - & - & - \\
\hline 54 & $497.5-507.0$ & 500.2 & 66.8 & 48.1 & 7.6 & $T$ & $\mathrm{~T}$ & - & - & - & - & - & - & - & 70.2 & - & - & - & 21.8 & - & - & - & - & - & - & 0.4 & - & - & $\mathrm{T}$ \\
\hline 56 & $516.5-526.0$ & 519.2 & 73.7 & 58.9 & 7.2 & P & $P$ & 2.0 & - & - & - & 8.0 & - & - & 74.1 & - & 7.1 & - & - & - & - & - & - & - & - & 1.5 & - & - & - \\
\hline 57 & $545.0-554.5$ & 547.2 & 70.7 & 54.3 & 7.1 & P & $\mathrm{T}$ & - & 18.5 & - & 2.1 & - & - & - & 69.5 & - & - & - & 1.8 & - & - & - & - & - & - & 0.9 & - & - & - \\
\hline \multicolumn{30}{|c|}{$2 \cdot 20 \mu$ Fraction } \\
\hline 1 & $0.0-9.0$ & 2.6 & 60.4 & 38.1 & - & - & - & 28.0 & - & 7.4 & 11.6 & - & 18.5 & 2.9 & - & - & - & - & - & - & 24.4 & 7.1 & - & - & - & - & - & - & - \\
\hline 9 & $75.5-85.0$ & 80.9 & 78.3 & 66.2 & - & - & - & 26.5 & - & 39.5 & 15.8 & - & 16.8 & 1.4 & - & - & - & - & - & - & - & - & - & - & - & - & - & - & - \\
\hline 13 & $113.5-123.0$ & 115.9 & 74.4 & 60.0 & - & - & - & 23.7 & - & 26.5 & 14.0 & - & 20.5 & 3.2 & - & 9.8 & 2.5 & - & - & - & - & - & - & - & - & - & - & - & - \\
\hline 16 & $142.0-151.5$ & 150.9 & 87.0 & 79.6 & - & P & - & 7.9 & - & - & 11.8 & - & 7.5 & 2.3 & 15.0 & - & 35.2 & - & - & - & 20.3 & - & - & - & - & - & - & - & - \\
\hline 17 & $151.5-161.0$ & 154.1 & 85.9 & 77.9 & - & A & - & - & - & - & 10.7 & - & - & 2.0 & 70.0 & - & - & - & - & - & - & - & - & - & 17.2 & - & - & - & - \\
\hline \multirow[t]{2}{*}{18} & $161.0-170.5$ & 163.4 & 84.6 & 76.0 & - & P & - & 1.3 & - & - & 7.7 & - & - & - & 85.2 & - & - & - & - & 5.7 & - & - & - & - & - & - & - & - & - \\
\hline & & 165.6 & 89.0 & 82.8 & - & $\mathbf{P}$ & - & - & - & - & 5.7 & - & - & - & 68.0 & - & - & - & - & 5.8 & - & - & - & 20.5 & - & - & - & - & - \\
\hline 20 & $180.0-189.5$ & 182.5 & 80.7 & 69.9 & - & $P$ & - & - & - & - & 3.4 & - & - & - & 84.2 & - & 2.0 & - & - & 10.5 & - & - & - & - & - & - & - & - & - \\
\hline 23 & 208.5-218.0 & 210.9 & 78.4 & 66.2 & - & A & - & 0.6 & - & - & - & - & - & - & 60.2 & - & 1.4 & 37.7 & - & - & - & - & - & - & - & - & - & - & - \\
\hline 25 & $227.5-237.0$ & 229.9 & 78.0 & 65.6 & - & A & - & 2.4 & - & - & - & - & - & - & 70.0 & - & 2.8 & 22.4 & - & 2.4 & - & - & - & - & - & - & - & - & - \\
\hline 30 & $269.5-279.0$ & 270.6 & 74.5 & 60.1 & - & A & - & 1.0 & - & - & 15.4 & - & 4.3 & 6.9 & 13.0 & - & 53.9 & - & - & - & - & - & - & - & 5.5 & - & - & - & - \\
\hline 31 & $279.0-288.5$ & 281.6 & 71.8 & 56.0 & - & P & - & 1.9 & - & - & 18.6 & - & - & - & 63.2 & - & 15.3 & - & - & 0.9 & - & - & - & - & - & - & - & - & - \\
\hline 36 & $326.5-336.0$ & 327.8 & 72.7 & 57.3 & - & $\mathrm{T}$ & $\mathrm{T}$ & - & - & - & 5.5 & - & - & - & 41.8 & - & 47.1 & - & 1.0 & 2.4 & - & - & - & - & 2.3 & - & $\mathrm{T}$ & P & - \\
\hline 38 & $345.5-355.0$ & 346.5 & 65.0 & 45.3 & - & A & $\mathrm{T}$ & - & - & - & 6.3 & - & 2.9 & - & 61.1 & - & 17.7 & - & - & - & - & - & - & - & 9.7 & 2.3 & - & P & - \\
\hline 40 & $364.5-374.0$ & 366.5 & 57.9 & 34.2 & - & P & P & - & - & - & - & - & - & - & 74.7 & - & 5.6 & - & 19.2 & - & - & - & - & - & - & 0.5 & - & - & - \\
\hline 42 & 383.5-393.0 & 386.4 & 68.2 & 50.3 & - & $\mathbf{P}$ & A & - & - & - & - & - & - & - & 81.0 & - & 15.9 & - & - & - & - & - & - & - & - & 3.1 & - & - & - \\
\hline 44 & $402.5-412.0$ & 404.1 & 67.4 & 49.1 & - & P & $\mathrm{P}$ & - & - & - & - & - & - & - & 96.5 & - & 2.9 & - & - & - & - & - & - & - & - & 0.5 & - & - & - \\
\hline 46 & $421.5-431.0$ & 424.0 & 66.1 & 47.0 & - & P & P & - & - & - & - & - & - & - & 51.8 & - & 28.0 & - & 13.0 & - & - & - & - & - & - & 7.2 & - & - & - \\
\hline 48 & $440.5-450.0$ & 442.6 & 62.2 & 41.0 & - & $P$ & $P$ & - & - & - & - & - & - & - & 56.7 & - & 4.6 & - & 36.2 & - & - & - & - & - & - & 2.5 & - & - & - \\
\hline 49 & $450.0-459.5$ & 452.1 & 68.3 & 50.5 & - & P & P & - & - & - & 13.1 & - & - & - & 54.9 & - & 6.4 & - & 24.6 & - & - & - & - & - & - & 0.9 & - & - & - \\
\hline
\end{tabular}




\begin{tabular}{|c|c|c|c|c|c|c|c|c|c|c|c|c|c|c|c|c|c|c|c|c|c|c|c|c|c|c|c|c|c|}
\hline Core & $\begin{array}{c}\text { Cored } \\
\text { Interval } \\
\text { Below Sea } \\
\text { Floor }(\mathrm{m})\end{array}$ & $\begin{array}{l}\text { Sample Depth } \\
\text { Below Sea } \\
\text { Floor }(\mathrm{m})\end{array}$ & 芒 & 彥 & हु & $\frac{\text { 。 }}{3}$ & $\stackrel{0}{\overline{3}}$ & 䞤 & हैं & $\frac{\dot{5}}{\dot{x}}$ & $\frac{\text { 렬 }}{2}$ & $\begin{array}{l}\overrightarrow{0} \\
\ddot{x}\end{array}$ & $\frac{\pi}{\Sigma}$ & $\frac{\dot{g}}{\tilde{c}}$ & 递 & 를 & 郎 & $\overrightarrow{\vec{E}}$ & $\stackrel{\overrightarrow{\mathrm{d}}}{\mathrm{C}}$ & 离 & 商 & 哭 & 谙 & हुं & 轺 & 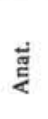 & ఫुँ & $\overline{3}$ & $\stackrel{\infty}{5}$ \\
\hline 51 & $469.0-478.5$ & 470.9 & 67.2 & 48.7 & - & $P$ & $\mathbf{P}$ & - & - & - & - & - & - & - & 60.3 & - & 16.9 & - & 20.2 & - & - & - & - & - & - & 2.7 & - & - & - \\
\hline 52 & $478.5-488.0$ & 481.3 & 58.1 & 34.5 & - & $P$ & $P$ & - & - & - & - & - & - & - & 44.2 & - & - & - & 54.1 & - & - & - & - & - & - & 1.7 & - & - & - \\
\hline 54 & $497.5-507.0$ & 500.2 & 70.3 & 53.6 & - & 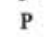 & $\mathrm{T}$ & 1.1 & - & - & - & - & - & - & 85.7 & - & - & - & 12.5 & - & - & - & - & - & - & 0.8 & - & - & $\mathrm{T}$ \\
\hline 56 & $516.5-526.0$ & 519.2 & 74.6 & 60.3 & - & P & P & 11.9 & - & - & - & 1.2 & - & - & 59.8 & - & 15.2 & - & - & 4.4 & - & - & - & - & - & 7.5 & - & $T$ & - \\
\hline 57 & $545.0-554.5$ & 547.2 & 71.2 & 55.0 & - & P & T & - & 43.9 & - & 1.0 & - & - & - & 50.3 & - & - & - & 3.8 & - & - & - & - & - & - & 1.0 & - & - & - \\
\hline \multicolumn{30}{|c|}{$<2 \mu$ Fraction } \\
\hline 1 & $0.0-9.0$ & 2.6 & 97.9 & 96.7 & - & - & - & 19.6 & - & - & 17.9 & 11.0 & 20.3 & - & 19.2 & - & - & - & - & - & 2.5 & 9.3 & - & - & - & - & - & - & - \\
\hline 7 & $56.5-66.0$ & 58.9 & 97.2 & 95.6 & - & - & - & 20.7 & - & - & 10.4 & 12.8 & 41.4 & - & 14.8 & - & - & - & - & - & - & - & - & - & - & - & - & - & - \\
\hline 9 & $75.5-85.0$ & 80.9 & 88.6 & 82.1 & - & - & - & 10.5 & - & 16.8 & - & 7.3 & 14.7 & - & 19.8 & 30.9 & - & - & - & - & - & - & - & - & - & - & - & - & - \\
\hline 13 & $113.5-123.0$ & 115.9 & 92.7 & 88.6 & - & - & - & 7.1 & - & 4.9 & - & - & 6.9 & 2.6 & 35.2 & 41.5 & 1.8 & - & - & - & - & - & - & - & - & - & - & - & - \\
\hline 16 & $142.0-151.5$ & 150.9 & 96.0 & 93.8 & - & - & - & 3.5 & - & - & - & - & - & - & 96.5 & - & - & - & - & - & - & - & - & - & - & - & - & - & - \\
\hline 17 & $151.5-161.0$ & 154.1 & 88.6 & 82.2 & - & - & - & - & - & - & - & - & - & - & 90.7 & - & - & - & - & - & - & - & 6.4 & - & 2.9 & - & - & - & - \\
\hline \multirow[t]{2}{*}{18} & $161.0-170.5$ & 163.4 & 91.5 & 86.7 & - & - & - & - & - & - & - & - & - & - & 91.8 & - & - & - & - & - & 1.4 & - & 6.9 & - & - & - & - & - & - \\
\hline & & 165.6 & 91.3 & 86.3 & - & - & - & - & - & - & - & - & - & - & 76.7 & - & - & - & _- & - & 1.8 & - & 3.6 & 17.8 & - & - & - & - & - \\
\hline 20 & $180.0-189.5$ & 182.5 & 89.2 & 83.1 & - & - & - & - & - & - & 5.3 & - & - & - & 82.4 & - & - & - & - & 4.4 & - & - & 7.9 & - & - & - & - & - & - \\
\hline 23 & $208.5-218.0$ & 210.9 & 85.9 & 77.9 & - & - & - & - & - & - & - & - & - & - & 81.3 & - & - & 9.1 & - & - & - & - & 9.6 & - & - & - & - & - & - \\
\hline 25 & $227.5-237.0$ & 229.9 & 84.5 & 75.8 & - & $\mathrm{T}$ & - & - & - & - & - & - & - & - & 90.5 & - & - & - & - & - & - & - & 9.5 & - & - & - & - & - & - \\
\hline 30 & $269.5-279.0$ & 270.6 & 87.3 & 80.1 & - & $T$ & - & 2.0 & - & - & 5.7 & - & 10.3 & - & 70.0 & - & 1.7 & - & - & - & - & - & 4.9 & - & 5.3 & - & $\mathbf{P}$ & - & - \\
\hline 31 & $279.0-288.5$ & 281.6 & 84.6 & 76.0 & - & T & - & - & - & - & 4.1 & - & - & - & 84.6 & - & 2.0 & - & - & - & - & - & 9.3 & - & - & - & - & - & - \\
\hline 36 & $326.5-336.0$ & 327.8 & 83.3 & 73.8 & - & - & - & - & - & - & $\ldots$ & - & - & - & 85.7 & - & 3.4 & - & - & - & - & - & 10.9 & - & - & - & - & - & - \\
\hline 38 & $345.5-355.0$ & 346.5 & 75.0 & 61.0 & - & $\mathbf{P}$ & - & - & - & - & 1.9 & - & - & - & 89.0 & - & 1.8 & - & - & - & - & - & 3.6 & - & 2.7 & 1.0 & - & $\mathrm{T}$ & - \\
\hline 40 & $364.5-374.0$ & 366.5 & 73.8 & 59.1 & - & T & $\mathrm{T}$ & - & - & - & - & - & 4.0 & - & 90.9 & - & 0.7 & - & 2.0 & - & - & - & 2.3 & - & - & - & - & - & - \\
\hline 42 & $383.5-393.0$ & 386.4 & 71.4 & 55.3 & - & T & $\mathrm{T}$ & - & - & - & 1.6 & - & - & - & 92.8 & - & 1.6 & - & - & - & - & - & 2.9 & - & - & 1.1 & - & $\mathrm{T}$ & $\mathbf{P}$ \\
\hline 44 & $402.5-412.0$ & 404.1 & 78.4 & 66.3 & - & $\mathrm{T}$ & $\mathrm{T}$ & - & - & - & - & - & - & - & 93.4 & - & - & - & - & - & - & - & 6.1 & - & - & 0.6 & - & - & - \\
\hline 46 & $421.5-431.0$ & 424.0 & 77.6 & 64.9 & - & $\mathrm{T}$ & P & - & - & - & - & - & - & - & 90.4 & - & 2.0 & - & 0.7 & - & - & - & 5.5 & - & - & 1.3 & - & - & - \\
\hline 48 & $440.5-450.0$ & 442.6 & 75.1 & 61.1 & - & T & - & - & - & - & 1.4 & - & .- & - & 92.7 & - & 0.5 & - & 5.4 & - & - & - & - & - & - & - & - & - & $\mathrm{T}$ \\
\hline 49 & $450.0-459.5$ & 452.1 & 78.3 & 66.1 & - & - & - & - & - & - & - & - & - & - & 88.3 & - & - & - & 7.3 & - & - & - & 3.9 & - & - & 0.5 & - & - & $\mathrm{T}$ \\
\hline 51 & $469.0-478.5$ & 470.9 & 75.2 & 61.2 & - & - & $T$ & - & - & - & - & - & - & - & 84.7 & - & 5.7 & - & 1.6 & - & - & - & 7.0 & - & - & 1.0 & - & - & $\mathbf{P}$ \\
\hline 52 & $478.5-488.0$ & 481.3 & 74.6 & 60.4 & - & T & $\mathrm{T}$ & - & - & - & - & - & - & - & 89.2 & - & - & - & 7.0 & - & - & - & 3.0 & - & - & 0.8 & - & - & $\mathrm{T}$ \\
\hline 54 & $497.5-507.0$ & 500.2 & 77.2 & 64.4 & - & - & - & - & - & - & - & - & - & . - & 94.2 & - & - & - & 1.3 & - & - & - & 3.8 & - & - & 0.7 & - & - & $\mathrm{P}$ \\
\hline 56 & $516.5-526.0$ & 519.2 & 77.1 & 64.2 & - & - & - & - & - & - & - & 4.1 & - & - & 91.3 & - & 1.7 & - & - & - & - & - & 1.7 & - & - & 1.2 & - & - & - \\
\hline 57 & $545.0-554.5$ & 547.2 & 77.0 & 64.0 & - & - & - & - & 13.8 & - & - & - & - & - & 80.8 & - & - & - & 1.1 & - & - & - & 2.1 & - & - & 2.1 & - & - & $\mathbf{P}$ \\
\hline
\end{tabular}

${ }^{2}$ Peaks at $3.23 \mathrm{~A}$ and $2.145 \mathrm{~A}$ among others. This mineral's peaks closely match those of anorthoclase (JCPDS 9.478). $\mathrm{P}=$ present; $\mathrm{T}=$ trace; $\mathrm{A}=$ abundant.

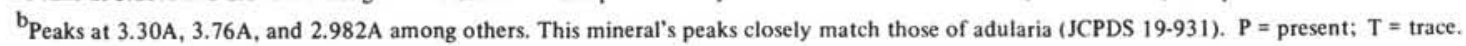

${ }^{\mathrm{C}}$ Narrow peaks at $4.05 \mathrm{~A}, 2.492 \mathrm{~A}$, and $2.843 \mathrm{~A}$ among others.

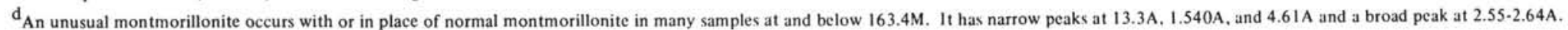

$\mathrm{e}_{\mathrm{P}}=$ present: $\mathrm{T}=$ trace.

${ }^{f}$ Peaks at 3.38A, 4.50A, and 3.46A among others; probably mordenite (JCPDS 6-239). $P=$ present: $T=$ trace.

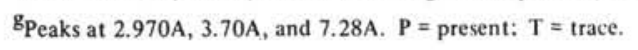


TABLE 16

Results of X-Ray Diffraction Analysis, Site 254

\begin{tabular}{|c|c|c|c|c|c|c|c|c|c|c|c|c|c|c|c|c|c|c|c|c|c|c|c|}
\hline Core & $\begin{array}{c}\text { Cored } \\
\text { Interval } \\
\text { Below Sea } \\
\text { Floor (m) }\end{array}$ & $\begin{array}{l}\text { Sample Depth } \\
\text { Below Sea } \\
\text { Floor (m) }\end{array}$ & 芯 & 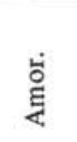 & નું & $\frac{\infty}{b}$ & $\stackrel{0}{5}$ & 范 & 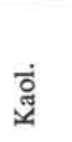 & 芯 & $\stackrel{\vec{J}}{\Sigma}$ & छ் & 蛋 & 鸸 & 完 & 空 & 商 & $\stackrel{\stackrel{0}{7}}{\vec{b}}$ & 氶 & $\begin{array}{l}\text { 鬲 } \\
\text { 吾 }\end{array}$ & 迅 & 迆 & ju \\
\hline \multicolumn{24}{|c|}{ Bulk Samples } \\
\hline \multirow[t]{2}{*}{2} & $5.5-15.0$ & 7.9 & 45.9 & 15.5 & 100.0 & - & - & - & - & - & - & - & - & - & - & - & - & - & - & - & - & - & - \\
\hline & & 12.4 & 47.9 & 18.5 & 100.0 & - & - & - & - & - & - & - & - & - & - & - & - & - & - & - & - & - & - \\
\hline 4 & $24.5-34.0$ & 26.9 & 46.8 & 16.9 & 100.0 & - & - & - & - & - & - & - & - & - & - & - & - & - & - & - & - & - & - \\
\hline 7 & $53.0-62.5$ & 59.9 & 47.0 & 17.2 & 100.0 & - & - & - & - & - & - & - & - & - & - & - & - & - & - & - & - & - & - \\
\hline 10 & $81.5-91.0$ & 87.6 & 45.9 & 15.5 & 100.0 & - & - & - & - & - & - & - & - & - & - & - & - & - & - & - & - & - & - \\
\hline 18 & $148.0-157.5$ & 154.9 & 51.2 & 23.7 & 97.6 & - & - & - & - & - & - & - & 2.4 & - & - & - & - & - & - & - & - & - & - \\
\hline \multirow[t]{2}{*}{20} & $167.0-176.5$ & 169.0 & 50.7 & 22.9 & 100.0 & - & - & - & - & - & - & - & - & - & - & - & - & - & - & - & - & - & - \\
\hline & & 169.8 & 74.7 & 60.4 & 87.7 & $\mathrm{~T}$ & $\mathrm{~T}$ & - & - & - & 4.1 & - & 6.8 & - & - & - & - & - & - & 1.4 & - & - & - \\
\hline 24 & $209.5-219.0$ & 210.6 & 85.5 & 77.3 & - & $\mathbf{P}$ & $\mathrm{T}$ & - & - & - & 66.6 & - & 20.5 & - & 8.3 & - & - & - & - & 3.4 & 1.2 & - & - \\
\hline 25 & $219.0-228.5$ & 225.7 & 83.5 & 74.3 & - & $\mathrm{P}$ & $\mathrm{P}$ & - & - & - & 45.1 & - & 32.7 & 3.0 & 19.2 & - & - & $\mathbf{P}$ & - & - & - & - & - \\
\hline 27 & $238.0-247.5$ & 242.2 & 86.7 & 79.2 & - & $\mathbf{P}$ & $\mathrm{P}$ & - & 3.7 & - & 46.7 & 4.9 & 16.9 & - & 27.8 & - & - & $\mathrm{P}$ & - & - & - & - & - \\
\hline 30 & $266.5-276.0$ & 267.7 & 89.4 & 83.4 & - & - & - & - & - & - & 95.5 & - & - & - & - & - & - & $\mathrm{T}$ & 4.5 & - & - & - & - \\
\hline \multicolumn{24}{|c|}{ 2-20 $\mu$ Fraction } \\
\hline 18 & $148.0-157.5$ & 154.9 & 73.7 & 58.9 & - & $P$ & $P$ & - & - & - & - & - & 92.2 & 1.3 & - & - & - & - & - & 6.5 & - & - & - \\
\hline \multirow[t]{2}{*}{20} & $167.0-176.5$ & 169.0 & 83.7 & 74.5 & - & $P$ & A & - & - & - & 23.6 & - & 27.6 & 36.4 & 1.9 & - & - & - & - & 10.5 & - & - & - \\
\hline & & 169.8 & 83.4 & 74.1 & - & $P$ & $\mathrm{P}$ & - & - & - & 20.9 & - & 68.0 & 3.0 & - & - & - & - & - & 8.2 & - & - & - \\
\hline 24 & $209.5-219.0$ & 210.6 & 79.7 & 68.3 & - & A & $\mathrm{P}$ & - & - & - & 60.2 & - & 5.2 & - & 28.2 & - & - & - & - & 4.9 & 1.4 & - & - \\
\hline 25 & $219.0-228.5$ & 225.7 & 71.5 & 55.5 & - & $\mathbf{P}$ & $\mathrm{P}$ & - & - & - & 24.6 & - & 20.1 & 5.8 & 33.1 & 16.5 & - & $\mathrm{T}$ & - & - & - & - & - \\
\hline 27 & $238.0-247.5$ & 242.2 & 73.3 & 58.3 & - & $P$ & $\mathrm{P}$ & - & - & - & 14.1 & 21.3 & 27.2 & - & 37.4 & - & - & $P$ & - & - & - & - & - \\
\hline 30 & $266.5-276.0$ & 267.7 & 79.0 & 67.1 & - & - & - & - & - & - & 100.0 & - & - & - & - & - & - & A & - & - & - & $\mathrm{T}$ & - \\
\hline \multicolumn{24}{|c|}{$<2 \mu$ Fraction } \\
\hline \multirow[t]{2}{*}{2} & $5.5-15.0$ & 7.9 & 97.8 & 96.6 & - & - & - & 15.3 & - & 28.0 & 35.9 & - & - & - & - & - & 10.4 & - & 10.4 & - & - & - & - \\
\hline & & 12.4 & 97.7 & 96.4 & - & - & - & 3.4 & - & 4.1 & 87.8 & - & - & - & - & - & 1.2 & - & 3.5 & - & - & - & - \\
\hline 4 & $24.5-34.0$ & 26.9 & 98.0 & 96.9 & - & - & - & 5.9 & - & 12.4 & 77.2 & - & - & - & - & - & 3.2 & - & 1.3 & - & - & - & - \\
\hline 7 & $53.0-62.5$ & 59.9 & 98.9 & 98.3 & - & - & - & 34.9 & - & - & 33.6 & - & - & - & - & - & 7.0 & - & 24.6 & - & - & - & - \\
\hline 10 & $81.5-91.0$ & 87.6 & 98.7 & 98.0 & - & - & - & 25.7 & - & 35.2 & 28.6 & - & - & - & - & - & 5.3 & - & 5.3 & - & - & - & - \\
\hline 18 & $148.0-157.5$ & 154.9 & 95.0 & 92.1 & - & A & $P$ & - & - & 16.6 & 47.5 & - & 17.1 & - & - & - & 1.8 & - & 11.3 & 5.8 & - & - & - \\
\hline \multirow[t]{2}{*}{20} & $167.0-176.5$ & 169.0 & 95.4 & 92.8 & - & - & - & - & - & - & 81.1 & - & - & 3.7 & - & - & 5.0 & - & - & 10.2 & - & - & - \\
\hline & & 169.8 & 91.8 & 87.3 & - & $\mathbf{P}$ & $P$ & - & - & - & 56.7 & - & - & - & - & - & - & - & 23.1 & 20.1 & - & - & - \\
\hline 24 & $209.5-219.0$ & 210.6 & 86.7 & 79.2 & - & - & - & - & - & - & 85.7 & - & - & - & 1.6 & - & - & - & 11.2 & - & 1.4 & - & - \\
\hline 25 & $219.0-228.5$ & 225.7 & 85.1 & 76.8 & - & - & - & - & - & - & 87.5 & - & - & - & 5.2 & - & - & - & 7.3 & - & - & - & - \\
\hline 27 & $238.0-247.5$ & 242.2 & 87.6 & 80.6 & - & $\mathrm{P}$ & $P$ & - & 5.4 & - & 55.1 & 2.9 & 2.9 & - & 16.4 & - & - & - & 17.3 & - & - & - & - \\
\hline 30 & $266.5-276.0$ & 267.7 & 82.0 & 71.9 & - & - & - & - & - & - & 62.2 & - & - & - & - & - & - & - & 37.8 & - & - & $\mathbf{P}$ & A \\
\hline
\end{tabular}

${ }^{\mathrm{a}}$ Peaks at $3.23 \AA$ and $2.145 \AA$ among others. This mineral's peaks closely match those of anorthoclase (JCPDS $\left.9-478\right)$. $\mathrm{A}=\mathrm{abundant} ; \mathrm{P}=$ present; $\mathrm{T}=$ trace.

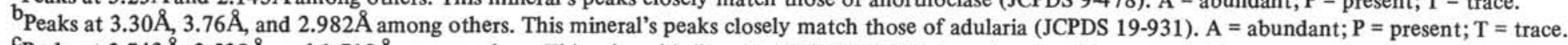

CPeaks at $2.743 \AA, 2.538 \AA$, and $1.719 \AA$ among others. This mineral is ilmenite (JCPDS 3-781). A = abundant; $\mathrm{P}=$ present; $\mathrm{T}=$ trace.

Narrow peaks at $9.60 \AA$ and $2.418 \AA$. 
TABLE 17

Results of X-Ray Diffraction Analysis, Site 255

\begin{tabular}{|c|c|c|c|c|c|c|c|c|c|}
\hline Core & $\begin{array}{c}\text { Cored } \\
\text { Interval } \\
\text { Below Sea } \\
\text { Floor }(\mathrm{m})\end{array}$ & $\begin{array}{l}\text { Sample Depth } \\
\text { Below Sea } \\
\text { Floor (m) }\end{array}$ & 苑 & 宫 & లే & हैّ & 䒿 & 莽 & 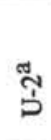 \\
\hline \multicolumn{10}{|c|}{ Bulk Sample } \\
\hline 5 & $42.0-51.5$ & 43.3 & 54.6 & 29.0 & 100.0 & - & - & - & $\mathrm{T}$ \\
\hline \multicolumn{10}{|c|}{ 2-20 $\mu$ Fraction } \\
\hline 5 & $42.0-51.5$ & 43.3 & 80.2 & 69.0 & - & 29.8 & 62.2 & 8.0 & A \\
\hline \multicolumn{10}{|c|}{$<2 \mu$ Fraction } \\
\hline 5 & $42.0-51.5$ & 43.3 & 96.5 & 94.6 & - & 100.0 & - & - & M \\
\hline
\end{tabular}

${ }^{\mathrm{a}}$ Peaks at $2.787 \AA, 2.689 \AA$, and $1.836 \AA$ among others. Its peaks closely match those of wilkeite (JCPDS $6-454$ ) and less closely those of apatite. $\mathrm{A}=$ abundant; $\mathrm{M}=$ major; $\mathrm{T}=$ trace. 
TABLE 18

Results of X-Ray Diffraction Analysis, Site $\mathbf{2 5 6}$

\begin{tabular}{|c|c|c|c|c|c|c|c|c|c|c|c|c|c|c|c|c|c|c|c|c|c|}
\hline Core & $\begin{array}{c}\text { Cored } \\
\text { Interval } \\
\text { Below Sea } \\
\text { Floor }(\mathrm{m})\end{array}$ & $\begin{array}{l}\text { Sample Depth } \\
\text { Below Sea } \\
\text { Floor }(\mathrm{m})\end{array}$ & 莒 & 宫 & गु & है & $\dot{\mathscr{H}}$ & 峁 & 竝 & $\begin{array}{l}\text { ठ্ } \\
\ddot{\Xi}\end{array}$ & 疍 & 롱 & $\overrightarrow{\tilde{\Sigma}}$ & 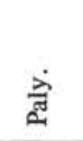 & $\vec{E}$ & छ & 承 & 㝕 & ) & 䍠 & $\stackrel{\pi}{\square}$ \\
\hline \multicolumn{22}{|c|}{ Bulk Sample } \\
\hline 1 & $0.0-9.5$ & 6.9 & 87.5 & 80.4 & - & 19.0 & - & 11.0 & 4.9 & 19.5 & 19.3 & - & 24.1 & - & - & 2.3 & - & - & - & - & - \\
\hline 3 & $47.5-57.0$ & 54.0 & 84.8 & 76.2 & - & 5.5 & - & 3.5 & 2.0 & 21.8 & 18.5 & 4.8 & 42.5 & - & - & - & - & - & 1.3 & - & - \\
\hline 4 & $85.5-95.0$ & 94.2 & 85.5 & 77.3 & 1.0 & 7.4 & - & 2.3 & - & 26.7 & 14.1 & - & 47.3 & - & - & - & - & - & - & 1.0 & $\mathrm{P}$ \\
\hline 5 & $123.5-133.0$ & 128.9 & 88.4 & 81.8 & - & 14.5 & - & 12.7 & 1.9 & 15.2 & 29.6 & 2.0 & 24.0 & - & - & - & - & - & - & - & - \\
\hline 7 & $209.0-218.5$ & 213.3 & 87.8 & 81.0 & - & 9.2 & 38.2 & 5.6 & - & - & 15.1 & - & 6.8 & - & 7.8 & 17.1 & - & - & - & - & - \\
\hline 8 & $237.5-247.0$ & 244.6 & 85.2 & 76.8 & - & 7.5 & 25.9 & 4.8 & - & - & 17.4 & - & 6.7 & - & 1.6 & 36.0 & - & - & - & - & - \\
\hline 9 & $247.0-256.5$ & 248.3 & 81.1 & 70.4 & 46.4 & 14.0 & - & 4.9 & - & - & 7.3 & - & 21.4 & - & - & 5.9 & - & - & - & - & - \\
\hline \multicolumn{22}{|c|}{ 2-20 $\mu$ Fraction } \\
\hline 1 & $0.0-9.5$ & 6.9 & 73.5 & 58.6 & - & 38.3 & - & 12.3 & 10.5 & 15.1 & 17.7 & - & - & - & - & 6.1 & - & - & - & - & - \\
\hline 3 & $47.5-57.0$ & 54.0 & 77.8 & 65.4 & - & 18.0 & - & 12.3 & 4.9 & 15.6 & 23.9 & 5.1 & 17.1 & - & - & - & - & - & 3.2 & - & - \\
\hline 4 & $85.5-95.0$ & 94.2 & 80.5 & 69.5 & - & 18.8 & - & 13.1 & 2.0 & 18.2 & 25.4 & 2.8 & 19.7 & - & - & - & - & - & - & - & $\mathbf{P}$ \\
\hline 5 & $123.5-133.0$ & 128.9 & 75.7 & 62.0 & - & 32.2 & - & 24.2 & 9.4 & 5.5 & 25.9 & 2.9 & - & - & - & - & - & - & - & - & - \\
\hline 7 & 209.0-218.5 & 213.3 & 72.3 & 56.7 & - & 15.3 & 39.8 & 7.6 & - & - & 5.0 & - & - & - & 6.3 & 26.1 & - & - & - & - & - \\
\hline 8 & $237.5-247.0$ & 244.6 & 60.1 & 37.7 & - & 15.6 & - & 8.1 & - & - & 5.2 & - & - & - & - & 69.8 & 1.3 & - & - & - & - \\
\hline 9 & $247.0-256.5$ & 248.3 & 77.3 & 64.5 & - & 36.2 & - & 17.2 & - & - & 12.8 & - & 20.5 & - & - & 10.2 & - & 3.1 & - & - & - \\
\hline \multicolumn{22}{|c|}{$<2 \mu$ Fraction } \\
\hline 1 & $0.0-9.5$ & 6.9 & 88.7 & 82.4 & - & 20.0 & - & 0.6 & 2.2 & 14.2 & 9.6 & - & 29.4 & 13.8 & - & 1.6 & - & - & - & 8.7 & - \\
\hline 3 & $47.5-57.0$ & 54.0 & 86.3 & 78.6 & - & 11.0 & - & 5.4 & 3.8 & 27.2 & 9.4 & 2.8 & 27.4 & - & - & - & - & - & 2.2 & 10.8 & - \\
\hline 4 & $85.5-95.0$ & 94.2 & 85.8 & 77.8 & - & 8.6 & - & 4.8 & - & 16.4 & 16.4 & - & 40.5 & - & - & - & - & - & - & 13.2 & $\mathbf{P}$ \\
\hline 5 & $123.5-133.0$ & 128.9 & 85.9 & 78.0 & - & 19.1 & - & 10.0 & - & 8.8 & 28.1 & - & 23.4 & - & - & - & - & - & - & 10.7 & - \\
\hline 7 & $209.0-218.5$ & 213.3 & 82.6 & 72.9 & - & 10.6 & 50.5 & 6.5 & - & - & 6.3 & - & 9.2 & - & 4.5 & 8.6 & - & - & - & 3.8 & - \\
\hline 8 & $237.5-247.0$ & 244.6 & 86.7 & 79.2 & - & 4.3 & 37.8 & 6.5 & - & - & 11.9 & - & 24.8 & - & 5.5 & 3.6 & - & - & - & 5.6 & - \\
\hline 9 & $247.0-256.5$ & 248.3 & 86.5 & 78.9 & - & 27.4 & - & 8.7 & - & - & 4.2 & - & 35.1 & - & - & 1.6 & - & - & - & 23.0 & - \\
\hline
\end{tabular}

${ }^{a}$ Narrow peaks at $4.63 \AA$ and $9.33 \AA . P=$ present. 
TABLE 19

Results of X-Ray Diffraction Analysis, Site 257

\begin{tabular}{|c|c|c|c|c|c|c|c|c|c|c|c|c|c|c|c|c|c|c|c|c|}
\hline Core & $\begin{array}{c}\text { Cored } \\
\text { Interval } \\
\text { Below Sea } \\
\text { Floor }(\mathrm{m})\end{array}$ & $\begin{array}{l}\text { Sample Depth } \\
\text { Below Sea } \\
\text { Floor (m) }\end{array}$ & 䞤 & 官 & $\frac{\dot{0}}{\pi}$ & 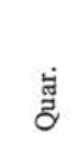 & में & 它 & 离 & $\begin{array}{l}\text { ठ் } \\
\text { }\end{array}$ & $\stackrel{\Xi}{2}$ & $\frac{\tilde{c}}{\Sigma}$ & 总 & 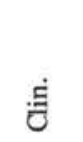 & ๕્๋ & 熍 & 茎 & $\stackrel{\varpi}{\square}$ & in & 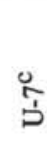 \\
\hline \multicolumn{21}{|c|}{ Bulk Sample } \\
\hline 1 & $0.0-9.5$ & 6.9 & 88.4 & 81.9 & - & 21.2 & - & 5.4 & 10.2 & 5.8 & 21.3 & 36.1 & - & - & - & - & - & - & - & - \\
\hline 2 & $9.5-19.0$ & 12.3 & 84.3 & 75.4 & - & 9.6 & - & 4.1 & 1.8 & 11.2 & 21.5 & 43.6 & - & 8.2 & - & - & - & - & - & - \\
\hline 3 & $47.5-57.0$ & 51.7 & 83.2 & 73.8 & - & 8.1 & - & 2.9 & - & 12.0 & 9.4 & 67.7 & - & - & - & - & - & $\mathrm{T}$ & - & - \\
\hline 4 & $85.5-95.0$ & 90.2 & 84.1 & 75.1 & - & 4.1 & 5.9 & 3.0 & 1.2 & - & 18.3 & 40.2 & 1.3 & 26.0 & - & - & - & - & - & - \\
\hline 5 & $123.5-133.0$ & 125.9 & 87.1 & 79.9 & - & 4.8 & 13.5 & 5.8 & 2.0 & 4.6 & 18.4 & 24.2 & 2.3 & 24.3 & - & - & - & - & - & - \\
\hline 6 & $161.5-171.0$ & 162.8 & 84.5 & 75.7 & - & 9.3 & - & 11.1 & 2.1 & - & 19.1 & 39.2 & - & 19.2 & - & - & - & - & - & - \\
\hline 7 & $199.5-209.0$ & 201.9 & 81.3 & 70.7 & 18.8 & 8.4 & - & 10.0 & - & 4.8 & 8.2 & 49.8 & - & - & - & - & - & - & - & - \\
\hline 8 & $237.5-247.0$ & 239.9 & 81.4 & 70.9 & 5.3 & 8.2 & - & 9.1 & - & 7.0 & 5.8 & 64.6 & - & - & - & - & - & - & - & - \\
\hline 9 & $247.0-256.5$ & 249.5 & 78.2 & 66.0 & - & 22.5 & - & 4.8 & 1.5 & - & 3.0 & 64.8 & - & - & 3.4 & - & - & - & - & - \\
\hline 10 & $256.5-263.0$ & 257.4 & 76.9 & 63.9 & - & 34.5 & - & 2.7 & - & - & 8.2 & 49.8 & - & - & 4.7 & - & - & - & - & - \\
\hline \multicolumn{21}{|c|}{ 2-20 $\mu$ Fraction } \\
\hline 1 & $0.0-9.5$ & 6.9 & 81.1 & 70.4 & - & 42.3 & - & 8.5 & $15.3^{\prime}$ & 3.2 & 12.7 & 9.9 & - & 8.2 & - & - & - & - & - & - \\
\hline 2 & $9.5-19.0$ & 12.3 & 71.5 & 55.5 & - & 30.1 & - & 5.4 & 3.7 & 8.9 & 20.9 & 13.3 & - & 17.7 & - & - & - & - & - & - \\
\hline 3 & $47.5-57.0$ & 51.7 & 70.8 & 54.5 & - & 31.2 & - & 7.9 & 2.9 & 14.8 & 28.7 & 14.4 & - & - & - & - & - & $\mathbf{P}$ & - & - \\
\hline 4 & $85.5-95.0$ & 90.2 & 59.9 & 37.4 & - & 10.2 & - & 3.7 & 2.9 & - & 11.5 & 7.2 & - & 64.5 & - & - & - & - & - & - \\
\hline 5 & $123.5-133.0$ & 125.9 & 65.6 & 46.2 & - & 9.9 & - & 9.1 & 1.6 & 4.0 & 8.3 & 11.2 & - & 56.0 & - & - & - & - & - & - \\
\hline 6 & $161.5-171.0$ & 162.8 & 66.3 & 47.3 & - & 12.9 & - & 19.0 & 2.3 & 3.9 & 13.6 & 8.0 & - & 40.4 & - & - & - & - & - & - \\
\hline 7 & $199.5-209.0$ & 201.9 & 77.0 & 64.1 & - & 17.2 & - & 37.7 & 2.3 & 7.6 & 23.1 & 12.1 & - & - & - & - & - & - & - & - \\
\hline 8 & $237.5-247.0$ & 239.9 & 76.2 & 62.8 & - & 19.2 & - & 40.0 & - & 10.6 & 11.5 & 18.7 & - & - & - & - & - & - & - & - \\
\hline 9 & $247.0-256.5$ & 249.5 & 74.0 & 59.4 & - & 26.9 & - & 16.3 & 1.9 & - & 20.6 & 29.8 & - & - & 3.2 & 1.4 & - & - & - & - \\
\hline 10 & $256.5-263.0$ & 257.4 & 68.3 & 50.5 & - & 56.6 & - & 10.8 & - & - & 13.9 & 15.1 & - & - & 3.6 & - & - & - & - & - \\
\hline \multicolumn{21}{|c|}{$<2 \mu$ Fraction } \\
\hline 1 & $0.0-9.5$ & 6.9 & 87.0 & 79.8 & - & 23.1 & - & 4.3 & 9.9 & - & 11.4 & 42.4 & - & - & - & - & 8.8 & - & - & - \\
\hline 2 & $9.5-19.0$ & 12.3 & 86.1 & 78.3 & - & 6.9 & - & 1.7 & 2.6 & 15.6 & 8.6 & 44.1 & - & 1.0 & - & - & 19.5 & - & - & - \\
\hline 3 & $47.5-57.0$ & 51.7 & 82.0 & 71.9 & - & 15.7 & - & 8.2 & 3.4 & 12.3 & 10.2 & 32.2 & - & - & - & - & 18.0 & $\mathrm{~T}$ & - & - \\
\hline 4 & $85.5-95.0$ & 90.2 & 80.2 & 69.1 & - & 5.2 & 18.7 & 5.6 & - & - & 7.6 & 36.9 & - & 11.2 & - & - & 14.6 & - & - & - \\
\hline 5 & $123.5-133.0$ & 125.9 & 81.1 & 70.5 & - & 7.1 & 14.5 & 7.0 & 1.3 & 4.1 & 10.0 & 20.7 & 2.0 & 17.4 & - & - & 15.9 & - & - & - \\
\hline 6 & $161.5-171.0$ & 162.8 & 82.0 & 71.8 & - & 9.5 & - & 12.1 & 2.6 & 5.5 & 4.3 & 41.4 & - & 13.5 & - & - & 10.8 & - & - & - \\
\hline 8 & $237.5-247.0$ & 239.9 & 84.7 & 76.1 & - & 11.6 & - & 10.3 & - & 7.0 & 6.4 & 53.7 & - & - & - & - & 10.9 & - & $P$ & - \\
\hline 9 & $247.0-256.5$ & 249.5 & 75.1 & 61.1 & - & 20.6 & - & 2.6 & - & - & 25.4 & 35.1 & - & - & 3.0 & - & 13.3 & - & - & A \\
\hline 10 & $256.5-263.0$ & 257.4 & 75.3 & 61.3 & - & 52.2 & - & 2.9 & - & - & 2.6 & 31.7 & - & - & 3.7 & - & 6.9 & - & - & - \\
\hline
\end{tabular}

${ }^{a}$ Narrow Peaks at $4.63 \AA$ and $9.33 \AA . P=$ present; $T=$ trace.

Broad peaks at $3.00 \AA, 4.94 \AA$, and $4.13 \AA$ among others. The peaks are similar in position, ratio, and shape to goethite and hematite. However, the unidentified mineral has several peaks not represented by goethite's or hematite's peaks. $\mathrm{P}=$ present.

'Very narrow peaks at $9.86 \AA, 2.492 \AA$, and $1.700 \AA$ among others. $\mathrm{A}=$ abundant. 
TABLE 20

Results of X-Ray Diffraction Analysis, Site 258

\begin{tabular}{|c|c|c|c|c|c|c|c|c|c|c|c|c|c|c|c|c|c|c|c|c|c|c|}
\hline Core & $\begin{array}{c}\text { Cored } \\
\text { Interval } \\
\text { Below Sea } \\
\text { Floor (m) }\end{array}$ & $\begin{array}{l}\text { Sample Depth } \\
\text { Below Sea } \\
\text { Floor (m) }\end{array}$ & 幽 & 峁 & गु & 营 & 己ٌ & $\dot{\mathscr{J}}$ & $\frac{0}{\frac{1}{1}}$ & 楽 & $\begin{array}{l}\dot{0} \\
\ddot{\Xi}\end{array}$ & $\stackrel{\Xi}{\Sigma}$ & 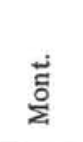 & 茞 & 봉 & 藌 & 家 & 仝 & 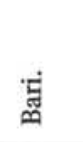 & 茎 & $\begin{array}{l}\text { 鬲 } \\
\text { 纭 }\end{array}$ & 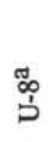 \\
\hline \multicolumn{23}{|c|}{ Bulk Samples } \\
\hline 1 & $0.0-9.5$ & 6.5 & 63.1 & 42.4 & 76.3 & 16.1 & 1.8 & - & 3.7 & - & - & - & - & - & - & - & 2.0 & - & - & - & - & - \\
\hline 3 & $47.5-57.0$ & 48.4 & 57.2 & 33.2 & 95.4 & - & 4.6 & - & - & - & - & - & - & - & - & - & - & - & - & - & - & - \\
\hline 4 & $85.5-95.0$ & 86.8 & 63.7 & 43.3 & 78.5 & - & 14.3 & - & 5.9 & - & 1.3 & - & - & - & - & - & - & - & - & - & - & - \\
\hline 6 & $142.5-152.0$ & 149.7 & 56.9 & 32.6 & 83.2 & - & 0.7 & 3.1 & - & - & - & - & 10.2 & - & - & - & 2.7 & - & - & - & - & - \\
\hline 10 & $199.5-206.0$ & 201.6 & 60.1 & 37.7 & 69.1 & - & 0.6 & 8.0 & - & - & - & - & 18.0 & 0.5 & - & - & 2.3 & - & 1.4 & - & - & - \\
\hline 12 & $234.5-244.0$ & 240.3 & 77.0 & 64.1 & 22.8 & - & 1.6 & 40.8 & - & - & - & - & 30.2 & 2.2 & - & - & 0.7 & - & 1.8 & - & - & - \\
\hline \multirow[t]{2}{*}{14} & $263.0-272.5$ & 263.0 & 83.0 & 73.4 & - & - & 2.4 & 55.9 & - & 2.0 & 2.5 & 2.5 & 11.0 & 4.1 & 16.8 & - & 0.4 & - & 2.3 & - & - & - \\
\hline & & 263.5 & 82.7 & 73.0 & - & - & 3.8 & 46.9 & - & - & 3.5 & 2.3 & 19.1 & 0.7 & 19.4 & - & - & - & 4.3 & - & - & - \\
\hline 15 & $282.0-291.5$ & 284.7 & 79.5 & 67.9 & 6.4 & - & 3.7 & 20.0 & - & - & 6.9 & 4.6 & 55.6 & 0.6 & 1.2 & - & - & - & 1.0 & - & - & - \\
\hline 16 & $301.0-310.5$ & 308.1 & 73.7 & 58.9 & 18.3 & - & 3.8 & 6.5 & - & - & 9.2 & 3.8 & 56.2 & - & 2.2 & - & - & - & - & - & - & - \\
\hline 17 & $320.0-329.0$ & 327.4 & 80.7 & 69.8 & 10.1 & - & 4.3 & 27.4 & - & - & 6.4 & 6.7 & 43.8 & 1.3 & - & - & - & - & - & - & - & - \\
\hline 18 & $339.0-348.5$ & 341.5 & 83.7 & 74.5 & 8.6 & - & 2.7 & 59.5 & - & - & 3.5 & 3.9 & 17.9 & 3.2 & 0.7 & - & - & - & - & - & - & - \\
\hline 21 & $405.5-415.0$ & 405.7 & 79.6 & 68.1 & - & - & 12.0 & 39.2 & 1.7 & - & 4.7 & 7.4 & 30.8 & 4.1 & - & - & - & - & - & - & - & - \\
\hline 22 & $435.0-444.5$ & 441.7 & 77.1 & 64.2 & - & - & 17.8 & - & - & - & 5.1 & 4.6 & 71.3 & - & - & - & 1.2 & - & - & - & - & - \\
\hline 23 & $472.0-481.5$ & 474.4 & 76.1 & 62.7 & - & - & 5.5 & - & - & - & 16.1 & 6.5 & 71.9 & - & - & - & - & - & - & - & - & - \\
\hline 24 & $510.0-519.5$ & 516.5 & 81.6 & 71.2 & 57.6 & - & 1.4 & - & 6.3 & - & 5.8 & - & 23.3 & - & - & - & 5.6 & - & - & - & - & - \\
\hline 25 & $519.5-525.0$ & 521.9 & 90.6 & 85.3 & - & - & 3.3 & - & 15.6 & - & 57.2 & - & 13.0 & - & - & 10.9 & - & - & - & - & - & $\mathrm{P}$ \\
\hline \multicolumn{23}{|c|}{ 2-20 $\mu$ Fraction } \\
\hline 1 & $0.0-9.5$ & 6.5 & 80.0 & 68.7 & - & - & 41.1 & - & 22.5 & 6.8 & 7.5 & 11.4 & - & - & 4.5 & - & 6.3 & - & - & - & - & - \\
\hline 3 & $47.5-57.0$ & 48.4 & 78.9 & 67.0 & - & - & 57.3 & - & 15.8 & 5.3 & 7.4 & 11.1 & - & - & 3.1 & - & - & - & - & - & - & - \\
\hline 4 & $85.5-95.0$ & 86.8 & 77.6 & 65.0 & - & - & 55.9 & - & 20.3 & - & 11.9 & 8.9 & - & - & 2.9 & - & - & - & - & - & - & - \\
\hline 6 & $142.5-152.0$ & 149.7 & 71.4 & 55.2 & - & - & 29.6 & 9.2 & 3.3 & 1.4 & - & 14.7 & 10.0 & 2.7 & 8.1 & - & 6.2 & - & 15.0 & - & - & - \\
\hline 10 & $199.5-206.0$ & 201.6 & 80.3 & 69.3 & - & - & 7.4 & 34.4 & - & - & - & 4.5 & 38.2 & 3.7 & 0.9 & - & 0.9 & - & 10.0 & - & - & - \\
\hline 12 & $234.5-244.0$ & 240.3 & 79.7 & 68.3 & - & - & 7.3 & 64.1 & 1.5 & 1.0 & - & 4.5 & 12.5 & 3.3 & 0.8 & - & - & - & 5.1 & - & - & - \\
\hline \multirow[t]{2}{*}{14} & $263.0-272.5$ & 263.0 & 70.7 & 54.2 & - & - & 3.6 & 57.3 & - & - & 1.5 & 1.8 & - & 4.6 & 22.0 & - & 0.8 & - & 8.3 & - & - & - \\
\hline & & 263.5 & 70.7 & 54.3 & - & - & 6.3 & 34.1 & - & - & 2.0 & 2.3 & - & 2.7 & 41.5 & - & 2.5 & - & 8.6 & - & - & - \\
\hline 15 & 282.0-291.5 & 284.7 & 68.0 & 50.0 & - & - & 14.6 & - & 2.8 & - & 18.2 & 6.8 & 27.8 & - & 28.0 & - & - & - & 1.7 & - & - & - \\
\hline 16 & $301.0-310.5$ & 308.1 & 77.8 & 65.4 & - & - & 14.3 & 23.2 & 3.2 & - & 13.8 & 9.7 & 31.5 & - & 1.5 & - & - & - & 2.9 & - & - & - \\
\hline 17 & $320.0-329.0$ & 327.4 & 79.3 & 67.7 & - & - & 13.3 & 17.8 & 4.6 & - & 16.0 & 16.2 & 26.7 & 2.1 & - & - & 1.1 & - & 2.3 & - & - & - \\
\hline 18 & $339.0-348.5$ & 341.5 & 80.2 & 69.1 & - & - & 9.1 & 65.9 & 3.1 & 0.9 & 6.3 & 6.7 & - & 3.1 & 2.3 & - & 0.6 & - & 2.0 & - & - & - \\
\hline 21 & $405.5-415.0$ & 405.7 & 74.8 & 60.6 & - & - & 23.2 & 24.9 & 7.5 & 1.5 & 9.0 & 9.9 & 22.5 & - & - & - & - & - & 1.5 & - & - & - \\
\hline 22 & $435.0-444.5$ & 441.7 & 70.4 & 53.7 & - & - & 32.9 & - & 11.0 & 1.7 & 11.5 & 12.4 & 25.8 & - & - & - & 4.8 & - & - & - & - & - \\
\hline 23 & $472.0-481.5$ & 474.4 & 67.8 & 49.8 & - & - & 11.3 & - & 5.0 & 1.3 & 25.5 & 15.3 & 39.8 & - & - & - & 1.8 & - & - & - & - & - \\
\hline 24 & $510.0-519.5$ & 516.5 & 80.7 & 69.8 & - & - & 8.5 & - & 31.7 & - & 4.4 & 1.9 & 44.3 & - & - & - & 9.2 & - & - & - & - & - \\
\hline 25 & $519.5-525.0$ & 521.9 & 84.9 & 76.3 & - & - & 6.1 & - & 31.4 & - & 11.6 & - & 7.8 & - & - & 19.8 & - & - & - & - & 23.2 & $P$ \\
\hline
\end{tabular}




\begin{tabular}{|c|c|c|c|c|c|c|c|c|c|c|c|c|c|c|c|c|c|c|c|c|c|c|}
\hline Core & $\begin{array}{c}\text { Cored } \\
\text { Interval } \\
\text { Below Sea } \\
\text { Floor }(\mathrm{m})\end{array}$ & $\begin{array}{l}\text { Sample Depth } \\
\text { Below Sea } \\
\text { Floor }(\mathrm{m})\end{array}$ & 葛 & 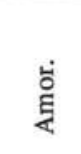 & गु & 党 & 㟧 & $\dot{\vec{g}}$ & 它 & 竎 & $\begin{array}{l}\dot{0} \\
\ddot{g}\end{array}$ & 茎 & $\overrightarrow{\tilde{\Sigma}}$ & ت्ञ & 离 & E્ & 完 & 仓ٕ. & 院 & 壆 & $\begin{array}{l}\text { 鬲 } \\
\text { 吾 }\end{array}$ & 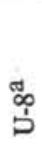 \\
\hline \multicolumn{23}{|c|}{$<2 \mu$ Fraction } \\
\hline 1 & $0.0-9.5$ & 6.5 & 92.2 & 87.7 & - & - & 9.5 & - & - & - & 42.0 & 14.0 & 30.6 & - & - & - & 3.9 & - & - & - & - & - \\
\hline 3 & $47.5-57.0$ & 48.4 & 86.9 & 79.5 & - & - & 11.8 & - & - & - & 48.0 & 17.5 & 16.0 & - & - & - & - & 6.7 & - & - & - & - \\
\hline 4 & $85.5-95.0$ & 86.8 & 85.1 & 76.8 & - & - & 7.4 & - & - & - & 36.2 & 14.9 & 39.0 & - & - & - & - & 2.5 & - & - & - & - \\
\hline 6 & $142.5-152.0$ & 149.7 & 85.1 & 76.7 & - & - & 3.5 & 38.9 & - & - & - & 4.7 & 38.4 & 2.0 & 1.2 & - & 0.9 & - & 7.4 & 2.9 & - & - \\
\hline 10 & $199.5-206.0$ & 201.6 & 82.4 & 72.5 & - & - & 3.9 & 42.5 & - & - & - & 2.6 & 28.3 & 1.5 & - & - & 0.3 & - & 10.9 & 10.1 & - & - \\
\hline 12 & $234.5-244.0$ & 240.3 & 81.7 & 71.4 & - & - & 0.3 & 50.6 & - & - & - & 2.4 & 37.9 & 1.7 & - & - & 0.4 & - & 1.8 & 4.9 & - & - \\
\hline \multirow{2}{*}{14} & $263.0-272.5$ & 263.0 & 85.0 & 76.6 & - & - & 2.0 & 64.0 & - & - & 1.7 & 1.4 & 19.8 & 5.8 & 0.5 & - & - & - & 1.4 & 3.6 & - & - \\
\hline & & 263.5 & 89.0 & 82.9 & - & - & 5.5 & 64.9 & - & - & 2.2 & - & 15.2 & 6.5 & - & - & 0.6 & - & 3.0 & 2.0 & - & - \\
\hline 15 & $282.0-291.5$ & 284.7 & 79.4 & 67.9 & - & - & 12.5 & 10.3 & - & - & 13.5 & 4.0 & 40.2 & - & 6.5 & - & - & - & 4.4 & 8.6 & - & - \\
\hline 16 & $301.0-310.5$ & 308.5 & 84.0 & 74.9 & - & - & 5.0 & 30.0 & - & - & 6.7 & 15.2 & 32.2 & - & - & - & - & - & 2.2 & 8.7 & - & - \\
\hline 17 & $320.0-329.0$ & 327.4 & 81.8 & 71.6 & - & - & 8.7 & 42.5 & - & - & 4.9 & 3.0 & 29.8 & 1.7 & - & - & - & - & 1.7 & 7.7 & - & - \\
\hline 18 & $339.0-348.5$ & 341.5 & 84.3 & 75.5 & - & - & 1.9 & 67.0 & - & - & 1.7 & 0.8 & 17.3 & 4.0 & - & - & - & - & 0.9 & 6.5 & - & - \\
\hline 21 & $405.5-415.0$ & 405.7 & 80.6 & 69.7 & - & - & 11.0 & 38.8 & - & - & 2.5 & 14.4 & 10.4 & - & - & - & - & - & - & 22.8 & - & - \\
\hline 22 & $435.0-444.5$ & 441.7 & 84.7 & 76.1 & - & - & 43.8 & - & - & - & 8.2 & 4.6 & 12.7 & - & - & - & - & - & - & 30.6 & - & - \\
\hline 23 & $472.0-481.5$ & 474.4 & 80.2 & 69.1 & - & - & 8.9 & - & - & - & 19.0 & 6.6 & 52.2 & - & - & - & - & - & - & 13.4 & - & - \\
\hline 24 & $510.0-519.5$ & 516.5 & 94.2 & 90.0 & - & - & - & - & - & - & 12.4 & 11.8 & 59.2 & - & - & - & - & - & - & 16.6 & - & - \\
\hline 25 & $519.5-525.0$ & 521.9 & 93.0 & 89.0 & - & - & 2.1 & - & - & - & 59.5 & - & 21.4 & - & - & 11.9 & - & - & - & 5.0 & - & - \\
\hline
\end{tabular}

${ }^{\mathrm{a}}$ Narrow peaks at $2.753 \AA$ and $3.006 \AA$ among others. $P=$ present. 